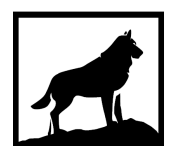

Michigan Technological

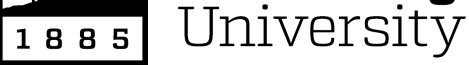

Michigan Technological University Digital Commons @ Michigan Tech

\title{
QUANTIFYING WATER RECHARGE AND WATER USE IN HAND DUG WELLS: A CASE STUDY OF THIAWOR, SENEGAL, WEST AFRICA
}

Celine Carus

Michigan Technological University, cmcarus@mtu.edu

Copyright 2020 Celine Carus

\section{Recommended Citation}

Carus, Celine, "QUANTIFYING WATER RECHARGE AND WATER USE IN HAND DUG WELLS: A CASE STUDY OF THIAWOR, SENEGAL, WEST AFRICA", Open Access Master's Report, Michigan Technological University, 2020.

https://doi.org/10.37099/mtu.dc.etdr/1024

Follow this and additional works at: https://digitalcommons.mtu.edu/etdr

Part of the African Languages and Societies Commons, Geology Commons, Social and Cultural Anthropology Commons, and the Water Resource Management Commons 


\title{
QUANTIFYING WATER RECHARGE AND WATER USE IN HAND DUG WELLS: A CASE STUDY OF THIAWOR, SENEGAL, WEST AFRICA
}

\author{
A REPORT \\ Submitted in partial fulfillment of the requirements for the degree of \\ MASTER OF SCIENCE \\ In Geology \\ MICHIGAN TECHNOLOGICAL UNIVERSITY \\ 2020 \\ (C) 2020 Celine Carus
}


This report has been approved in partial fulfillment of the requirements for the Degree of MASTER OF SCIENCE in Geology.

Department of Geological and Mining Engineering and Sciences

\author{
Report Co-Advisor: John S. Gierke \\ Report Co-Advisor: $\quad$ Kari Henquinet \\ Committee Member: $\quad$ David Watkins \\ Department Chair: Aleksey Smirnov
}




\section{TABLE OF CONTENTS}

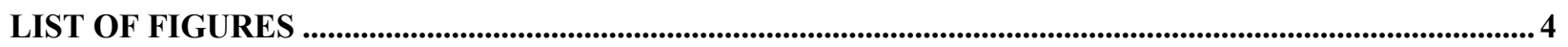

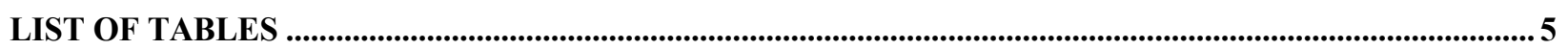

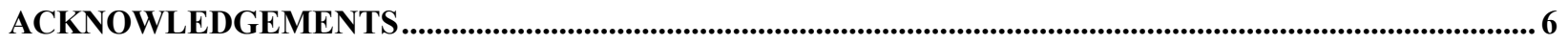

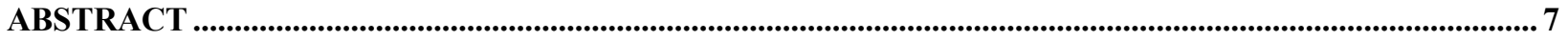

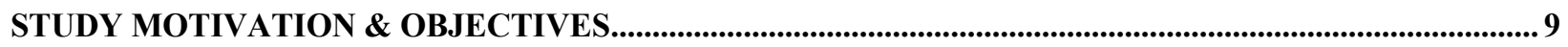

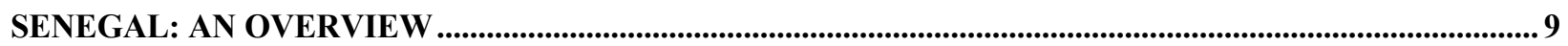

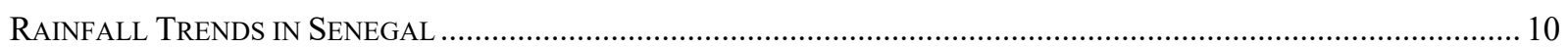

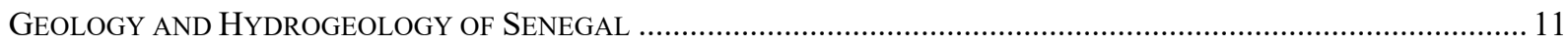

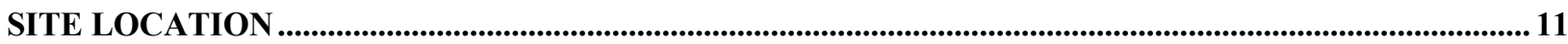

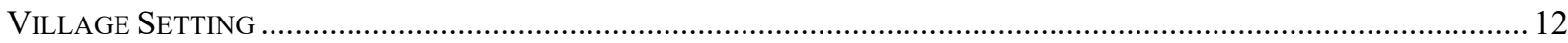

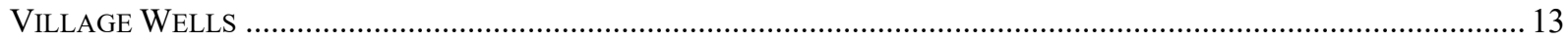

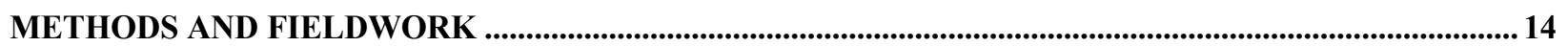

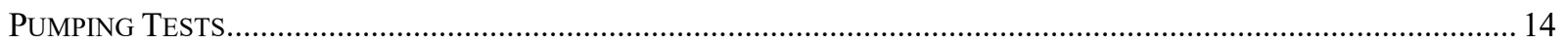

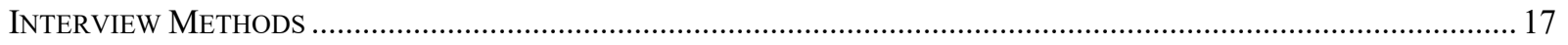

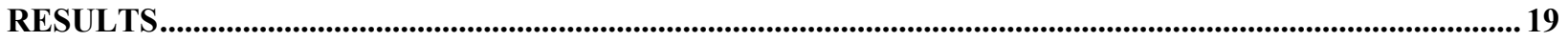

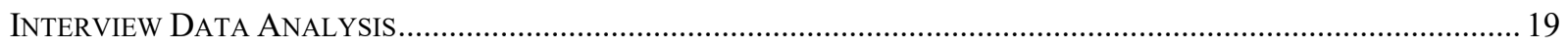

PumPING TeSt ReSUltS AND DATA ANALYSIS Using AQTESOLV ..............................................................2

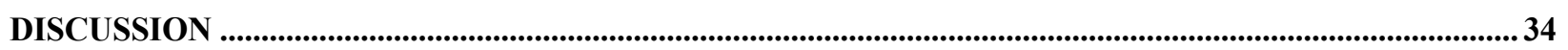

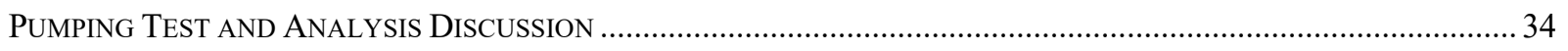

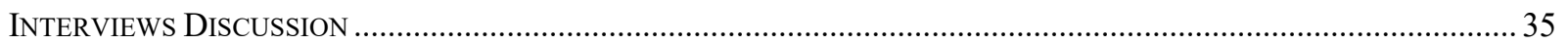

FUTURE WORK \& RECOMMENDATIONS ....................................................................................................3

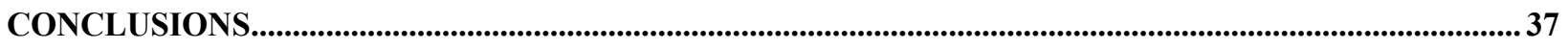

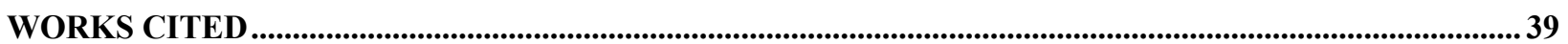




\section{List of Figures}

Figure 1: A compound well in Thiawor.......................................................................... 13

Figure 2: Constructed measurement tape with hollow container to make a sound when reaching

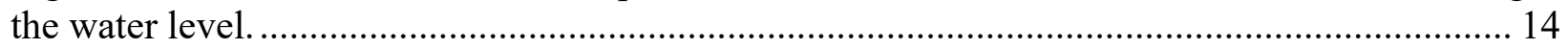

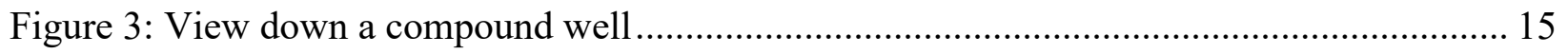

Figure 4: Two teams performing the pump tests at one of the village wells ........................... 15

Figure 5: Materials used to pump water from the wells ................................................. 15

Figure 6: Pouring the pumped water into laundry buckets for measurement .......................... 16

Figure 7: Afternoon water retrieval using the traditional pulley method ................................. 22

Figure 8: Diawara Well recovery phase of pumping test. Data fit with AQTESOLV to match parameters to the Moench (1997) solution, which accounts for pumping and recovery in a partially penetrating well with wellbore storage in a homogeneous, isotropic, unconfined aquifer.

Figure 9: Camara Well recovery phase of pumping test. Data fit with AQTESOLV to match parameters to the Moench (1997) solution, which accounts for pumping and recovery in a partially penetrating well with wellbore storage in a homogeneous, isotropic, unconfined aquifer.

Figure 10: Sankare Well recovery phase of pumping test. Data fit with AQTESOLV to match parameters to the Moench (1997) solution, which accounts for pumping and recovery in a partially penetrating well with wellbore storage in a homogeneous, isotropic, unconfined aquifer.

Figure 11: Danfakha Well recovery phase of pumping test. Data fit with AQTESOLV to match parameters to the Moench (1997) solution, which accounts for pumping and recovery in a partially penetrating well with wellbore storage in a homogeneous, isotropic, unconfined aquifer.

................................................................................................................. 31

Figure 12: Sunkaro Well recovery phase of pumping test. Data fit with AQTESOLV to match parameters to the Moench (1997) solution, which accounts for pumping and recovery in a partially penetrating well with wellbore storage in a homogeneous, isotropic, unconfined aquifer. 


\section{List of Tables}

Table 1.1 Pumping Test Data for each Well .................................................................... 17

Table 2.1 Parameter values of each well derived from Moench (1997) solution ....................... 27

Table 3.1 Percent drawdown and estimated percent maximum yield of wells.......................... 33 


\section{Acknowledgements}

I would first and foremost like to thank the entire community of Thiawor for enthusiastically and kindly welcoming me, a stranger to them, to share their lives and work with me. To my host family the Diawara, I have unending gratitude for the compassion, care, and understanding they showed me for two years as they helped me learn language, customs, and culture. My time in Senegal would have been very different without these relationships. Additionally, without the constant support of fellow volunteers and Peace Corps Senegal staff I would have never had as fulfilling and productive a service. Thank you to the volunteers who transported materials to and from the United States for me on their personal trips, as well as to those who stayed with me for motivational and research support; there are more than I could name. I would like to give special thanks to the Michigan Technological University professors Dr. Kari Henquinet, Dr. John Gierke, Dr. Watkins, and Dr. Blair Orr, for a multitude of reasons. Firstly, for their active support in helping develop my research, but more importantly for their personal care, empathy and understanding of the difficulties of international research and life. The responsive conversations concerning both research and everyday struggles mean more to me than I can adequately express. I thank my parents and personal friends for allowing me to share my experiences with them during their brief visits to Senegal - I know it also meant a lot to my community to have two parts of my life meet. To the larger Michigan Tech PCMI community; you offered me support and advice before, during, and after my service that prepared me and carried me through. 


\begin{abstract}
For many rural communities in Senegal, water is an essential life-giving need received only through a network of hand dug wells. Increasing rainfall variability in the Sahel has driven greater water insecurity for those communities that rely on rain-irrigated systems for agriculture. This study investigates the retrieval, purposes, and quantities of seasonal water usage on a small domestic scale, as well as an analysis of perceived water availability in the wells during the rainy season. Additionally, using a combination of interview data and pumping test data obtained from the village wells, water usage and estimated daily needs are calculated and compared to potential well productivity. The analyses of the community water needs from the surveys and capabilities of the wells to produce water confirm that the wells not only provide the current needs but improved pumping and/or well configurations could provide approximately 10 times the current usage.
\end{abstract}




\section{Introduction}

For much of the planet, water quality and water access are an increasingly important issue. In arid environments like the West African Sahel, average precipitation has been declining during the past century (Dietz et al., 2004) (Sissokho et al., 2011). The African continent is projected to be especially vulnerable to climate change, with drastic climatic shifts being reported in the last century, and predicted to continue (Field et al., 2014). Because of the increasing unpredictability of rainfall events, agricultural ways of life are at increased risk, and food security and water security for vulnerable populations are at risk (Verhagen et al., 2004). In a country like Senegal, where $73 \%$ of the population is involved in agricultural production as their primary occupation, this seasonal rainfall variability is of great importance to livelihoods, health, and economic stability (Serdeczny, 2016).

This study is located in the West African Sahel, which encompasses Senegal, The Gambia, Guinea-Bissau, Mali, Burkina Faso, Niger, Chad, Mauritania, and Cape Verde (Sissokho et al., 2011). Populations are growing in these countries, which means that whatever environmental impacts from climate change are occurring are impacting more people. Studies show that drier agricultural years in this region contribute to the continuation of cycles of poverty as resources are diminished and scarcer (Ludeke et al., 2004).

Water levels in wells, especially hand-dug wells, are indicators of drought conditions as the levels reflect the shallow subsurface water table elevation, which is recharged from infiltration. Many small villages and communities rely on hand-dug wells as their primary water source for drinking water and other domestic activities. It is thus important to understand what domestic household use is, especially when these small villages are accessing groundwater from solely hand dug wells. Changes in water levels can be an indicator of long-term changes in the future and can provide insight into strategies in the future of how or what can be done to manage access to water. Water scarcity can be linked to hygiene issues, economic issues, and a decline in well-being. Small household gardens are a source of nutrition and income in Senegal; difficulty in providing water to compound gardens can result in economic issues and gender-equality issues, as women are the primary gardeners and responsible for the majority of water retrieval for domestic activities.

The evaluation of vulnerability to water scarcity and potential approaches to enhance access to water supplies requires an understanding of community needs for water and the availability of water from the local resources. This project was designed to ascertain the current usage of water and the perceived needs and measure the production capacity of existing wells for satisfying current needs and availability for future increases in demands. Two types of data were collected to discern water needs and availability: manual pumping tests and interviews discussing household and domestic garden use on the village-level in a small village, Thiawor, in Senegal, West Africa. The purpose of the project was to distinguish the purposes and quantity of water available during the rainy season and to see if it meets the village demands currently, and how the village perceives local water availability. Recovery data taken from pumping tests were used to characterize basic hydrologic properties of the aquifer, as well as analyze the effectiveness of the data collection methods.

This research found that under idealized aquifer conditions in the rainy season, the wells in Thiawor provide between 49-72 liters per minute, assuming a 100\% drawdown of the estimated saturated depth in the dug wells. The village uses 7,560 liters per day in the rainy season to meet five core domestic needs. Overall perception of water availability in the village is that during the rainy season their needs are met. However, while these village needs are met during the rainy season, there are local water issues that contribute to water insecurity that exceeds availability of water in the well. 


\section{Study Motivation \& Objectives}

Significant water insecurity in the world is an increasing global concern. Information gathered from local perspectives is crucial in understanding impacts on vulnerable communities. If anthropologists, development professionals, and local leaders understand the impacts natural disasters have on communities, then they can better develop and implement strategies for mitigation and prevention including future planning for at-risk communities.

The selection for this case study location was based partially on the geographic location of the author during her Peace Corps service as an Agroforestry volunteer and her relationship with the community. Additionally, this location was determined to be an appropriate location for a study due to local population vulnerability and exposure to domestic water issues. This case study elaborates on water use in rural villages that do not have access to governmental infrastructure projects like solar pumps or running water. The purpose of this paper is to understand if water availabilitat the village level currently meets domestic needs seasonally. The report assesses the volume and allocation of water used daily in each household. Pumping tests were performed to characterize the production capacity for shallow groundwater resources.

In addition to pumping tests, oral interviews were conducted about domestic water use in a small rural village setting. The interviews were comprised of questions to the community about domestic water quantity use, and how much is allocated to each purpose. Average household consumption is quantified from these interviews, and peak water recharge in five productive village wells is measured, concluding with discussions of seasonal water demand and implications for the future. The information gathered seeks to discern impacts on vulnerable communities. Increased understanding of localized water resources in a community allows for more informed development and implementation of strategies of mitigation.

\section{Senegal: An Overview}

The Republic of Senegal is a country located in the westernmost portion of Africa, situated to the south of Mauritania and north of Guinea Bissau and Guinea, and bordered by the Atlantic Ocean to the west. The country is separated into 14 governmental regions and hosts large ethnic diversity. The country population is estimated at 15.7 million (The World Factbook, 2020). The official languages of Senegal are French and Wolof, although many different languages and ethnic groups are present. As of a 2018 estimate, annual population growth is at a rapid 2.8\% (The World Bank, 2019), and more than $60 \%$ of the population is under the age of 25 (The World Factbook, 2020). Rapid population growth and increased demand for resources could have important climate and water implications in the future.

Roughly $52 \%$ of the population is rural (The World Bank, 2019), with $46.8 \%$ of land available for agriculture (The World Factbook, 2020), and 42.8\% forested (2016 estimate) (The World Bank, 2019). More than $77 \%$ of the population is involved in some sort of agriculture activity (2007 estimate) (The World Factbook, 2020). As of last estimate in $2011,47 \%$ of the population is below the poverty line (The World Bank, 2019), and the unemployment rate is 6.7\% (2016 estimate) (International Labour Organization, 2020) (The World Factbook, 2020). There are many diverse ethnic groups and languages present in Senegal. Major agricultural products include: peanuts, millet, corn, sorghum, rice, cotton, tomatoes, green vegetables; cattle, poultry, pigs and fish (The World Bank, 2019). Agriculture is primarily rain-fed subsistence farming.

The terrain in Senegal is generally low, flat, rolling plains, with foothills toward the southeast region of Kedougou, and has a mean elevation of only 69 meters above sea level. Senegal has three climate regions within the Köppen-Geiger climate classification: warm desert, warm semi-arid, and tropical savannah. Senegal is part of a transitional zone that stretches from a more humid southern zone to the south and a drier Saharan desert climate to the north. Additional coastal and continental wind field processes (the Azores anticyclone, the North African Anticyclone, the Saharan thermal low and the Saint Helena anticyclone) influence the climate as well, leading to two prominent seasons of dry and wet 
(Ndione et al., 2017a). In Senegal-Oriental, where Thiawor is located, the rainy season is between June to October, and dry season is roughly from November to May.

The Sahelian region is semi-arid. Daytime temperatures can reach $40{ }^{\circ} \mathrm{C}$, but nightly temperatures can drop to around $14{ }^{\circ} \mathrm{C}$. Annual average rainfall is around $300-400 \mathrm{~mm}$, but fall between extremes, as rainfall usually occurs in fewer than 30 days of the year between the months of June and September.

Nomadic pastoralists are common in this area, grazing their flocks of cattle, goats, and sheep. In the more southern part of the Sahel, the soil is sandy and is well known as the Peanut Basin; peanut (or groundnut) is one of the most important crops in Senegal. The more northern parts of the Sahel often grow sorghum and have a similar climatic condition as neighboring Saharan countries Mali and Mauritania. The Southern regions of Kolda and Kedougou are hotter and humid, and average daily temperatures are above $30^{\circ} \mathrm{C}$ throughout the year. Rainfall is more frequent, at around $1000-1500 \mathrm{~mm}$ annually in the southernmost region. Here the rainy season lasts 2 to 3 months and extends into October. Agriculture is quite common in this region growing millet, maize, sorghum, rice, cassava, beans, sweet potatoes, and varieties of fruits. Tambacounda lies between the north and the south and is where the study site is located; it is the largest governmental region and comprises two of these climate regions - warm semi-arid to the north, and tropical savanna climate to the south. The study area, Thiawor, is in a transition zone between these two regions, with less frequent rainfall than the southern regions, and where many agricultural communities and semi-nomadic pastoralists coexist. There are 15 identified ecoregions within Senegal (Tappan et al., 2004). The country suffers from periodic droughts (The World Factbook, 2020).

More than 3 million Senegalese (including those of the case study area) lack basic access to water, defined as potable water that is from an improved source, provided collection time is not more than 30 minutes for a round trip, including wait time. This includes 'safety managed' water, which refers to drinking water from an improved water source that is located on premises, readily available when needed, and free of fecal and chemical contamination. More than $16 \%$ of the Senegalese population receives water from an unimproved water source; i.e. directly from a hand-dug well or spring without any sort of filtering or management, as is the case of Thiawor (UNICEF \& World Health Organization, 2012).

\section{Rainfall Trends in Senegal}

Rainfall patterns are variable in the Sahel, creating difficulty predicting potential impacts of water recharge, especially on a small local scale. Historically, Senegal has experienced significant drought periods. From 1950 to the mid 1980s rainfall declined rapidly, only partially recovering in the 1990s. However, while at present the rains in Senegal have remained steadily predictable, they are still 15\% below the averages recorded from 1920-1969. From 1975 to 2012 the temperature increased by $0.9{ }^{\circ} \mathrm{C}$, which, in turn, has amplified the effects from droughts. It is speculated that the warming of the North Atlantic Ocean has aided the rainfall increase after the recovery following the droughts in the 1980s (Hoerling et al., 2006). Since the entire country receives its annual rainfall in short intense rainfall periods, agriculturalists like those in the study area depend on rainfall amounts over $500 \mathrm{~mm}$ during this season to provide enough water for crops and livestock. Senegal as a whole receives the majority of its rain between June and September. The southern agricultural regions of Kolda, Kedougou and Tambacounda have historically received more than $500 \mathrm{~mm}$; however, the region of Tambacounda has historically experienced rainfall declines of $-150 \mathrm{~mm}$, or $30 \%$ below the mean rainfall (Funk et al., 2012) (Dai et al., 2004).

While the author was unable to access local rainfall data, broader precipitation analyses have been done to include the region of Tambacounda using data through 2010. Overall annual precipitation has increased since the droughts of the 1970s and 1980s; however, there is a "very large irregularity" in rainfall on a monthly scale. Upsurges of heavy rainfall are noted at the Tambacounda station, which may have consequences for groundwater recharge (Faye, 2019). Additional implications of rainfall variation include a change to the soil moisture deficit, an important precursor to groundwater recharge. In Senegal, with a majority of rainfall occurring in a few larger events, a lot of the precipitation will be lost to runoff 
due to soil infiltration capacities being exceeded. This means that less water will be available for recharge. The United States Geological Survey (USGS), United Sates Agency for International Development (USAID), and the Famine Early Warning Systems Network analyzed observed rainfall declines from 1960 to 2009, as well as temperature increases, based on weather stations located across the country (Funk et al., 2012). Climate trends for 2039 were predicted from these observations, which include the entire agriculturally productive regions of Senegal showing a $200-\mathrm{mm}$ decline in annual rainfall, and a temperature increase of $0.9^{\circ} \mathrm{C}$, amplifying the effect of drought over the Sahel. Predictions of future trends in rainfall in the Senegal-Gambia river basin specifically show a clear rainfall deficit. Combined with increasing potential evapotranspiration, hydrologic simulations of catchment discharge in the river basin may decrease to the same level as those observed during a particularly bad drought in the 1980s (Reulland et al., 2012). Thus, it is increasingly important to understand small-scale water usage demands in vulnerable populations that rely on rain-fed water systems, as they will be affected most significantly by changes in climate. Additionally, first steps in mitigation of water-related issues involves understanding the systems currently in place.

\section{Geology and Hydrogeology of Senegal}

The geology of Senegal dates back to the Archean and Proterozoic Birimian, which is consistent with much of West African geology. There are two major units that comprise the geology of Senegal: the Precambrian basement, which occupies the southeast of Senegal with some Cambrian sediments, and the large Mesozoic to recent sedimentary basin (Schlüter, 2006). Much of the interior of Senegal, including the majority of present-day Tambacounda is composed of Cenozoic continental sediments. The SenegalMauritanian basin formed during the rift of Pangea when forming the Atlantic Ocean.

Thiawor is located in the Senegal-Gambia River basin, which covers almost 77,100 square kilometers and shared within Guinea, Senegal, and The Gambia, and is part of a large watershed that is sourced from the Gambia River which originates at an altitude of $1150 \mathrm{~m}$ in Fouta-Djallon, Guinea. The total length of the main course is $1180 \mathrm{~km}$. In the interior, there are many tributaries, including one that passes north of Thiawor through Sandougou (Faye, 2019).

In Senegal, the main freshwater resources are divided in surface water and groundwater. Groundwaters occupy an important place and comprise the most exploited freshwater resource (Toure et al., 2010). A consideration with groundwaters include: wells screened in unconfined aquifers are more directly impacted by rainfall variation and drought than those in confined aquifers. Thus, a deeper confined aquifer is less likely to go dry than the more prevalent hand-dug wells relying on water table recharge. Additionally, since the water is hidden below the surface of the earth, this makes study more difficult to perform without additional financial support and interest from major universities, NGOs, and government bodies. Regarding the case of Thiawor, they are a small agricultural community with no government or NGO-sponsored projects, and thus much data is lacking to assist in the inception of their own community projects.

\section{Site Location}

Project Site: Thiawor, Tambacounda Region, Senegal $\left(13.8802333,-13.6309001\right.$ or $13^{\circ} 52^{\prime} 48.8^{\prime \prime} \mathrm{N}$ $\underline{\left.13^{\circ} 37^{\prime} 51.2^{\prime \prime} \mathrm{W}\right)}$

Thiawor is located in the Tambacounda region in Senegal, roughly $15 \mathrm{~km}$ north of the regional capital city of Tambacounda. The governmental region of Tambacounda is the largest geographical region of Senegal and touches neighboring countries Mali and Mauritania by its borders. The village of Thiawor is within the Commune of Sinthiou Malem, Department of Koussanar. Thiawor is considered a small bush village with an estimated population of roughly 386; however, it is larger than many of its surrounding villages. This population estimate was obtained through informal interviews conducted for this study in 2018. Thiawor lies within the eco-region Senegal Oriental, or Eastern Senegal, which is 
comprised primarily of dry savannah and is a transition into the more humid climates of the southern region of Kedougou and Kolda. The dominant vegetation is tree savanna (Earth Resources Observation and Science (EROS) Center, 2019). Most of the region of Tambacounda is involved in agricultural or pastoral activities. Thiawor is in the ecological range of Sudano-Sahelian rainfall with a mean average rainfall of $716.8 \mathrm{~mm}$ according to a 2017 report by the Journal of Geoscience and Environmental Protection (Ndione et al., 2017b). The author experienced two rainy seasons during her time there as a Peace Corps volunteer.

The community lies on the border with a pastoral region known as the Ferlo, with semi-nomadic communities to the north. The Ferlo is historically a zone of migration for large-scale herders, where surplus grass and rainy-season temporary water basins are used for animal pasture. Herders as a result migrate further south at the end of the rains, and toward the regions south like Tambacounda (Adriansen $\&$ Nielsen, 2002). The massive scale of animal grazing combined with increasing charcoal burning activity all contribute to soil degradation and deforestation in the region.

Some farmers keep livestock like cattle, sheep, and goats for food and extra income. Many households also own donkeys and horses for agricultural labor and transportation. Flatbed carts are often used or borrowed to haul goods and people to and from the market in the city of Tambacounda. There are currently no motorized public transportation options offered to the village. Thiawor is not connected to any sort of commercial power grid, but some compounds do have limited solar panel use for charging cell phones.

\section{Village Setting}

Almost all the families in the village of Thiawor would describe themselves as part of the Bambara ethnic group. While it is not uncommon for Bambara peoples to exist in Senegal, their presence is a minority in Senegal as a whole, with the largest concentrations existing in the Tambacounda and Kedougou regions which border Mali. In Thiawor as a result, many people are multilingual. Bambara are known agriculturalists, with the majority of the residents participating in subsistence farming of peanuts, millet, corn, and sorghum. This is accurate from field observations of village life in Thiawor. The other major ethnic groups present in Tambacounda are the Pulaar, Wolof, Mandinka, Soninke, and Sereer. The Pulaar, whose communities' border Thiawor to the north in a region called the Ferlo, are culturally pastoralists and semi-nomadic, associated with meat and dairy production. While their neighbors are semi-nomadic, Thiawor experiences seasonal fluxes in population; the majority of this is from a migration of younger men in the dry season participating in gold mining activities in Kedougou. Some compounds in Thiawor also do not have men in residence due to international migration; Thiawor is a subsistence farming community that often relies on money made externally for projects and extra income. Within the village itself there are no notable economic activities outside of two boutiques - small shops - which sell basic supplies to like sugar, oil, extra rice, flour, and tea for a small profit. Harvested crops are stored in huts, and compound garden vegetables are consumed or sold within the village. A portion of peanuts harvested are sold for income, and peanut haulm are used as fodder for animals, or also sold for additional money. In the dry season there are sometimes migratory Bassari peoples from the south that travel for menial labor like millet or corn pounding. Pastoralists with their goats, sheep, and cattle come through Thiawor from as far-reaching places like Niger during the dry season. At times extra income can be earned by allowing herders temporary residence to graze and fertilize the fields with their animals.

The predominant religion in the village is Islam; however, there are two practicing Christian families as well as a small Pentecostal church within the village to host Sunday prayer attendees from other communities. Islamic religious holidays like Ramadan and Tabaski (Eid al-Adha) are observed, as is Noel (Christmas) to a lesser degree. Those who do identify as Muslim do not always practice daily prayer five times. Polygamy is legal in Senegal, with men able to marry up to four wives; this is dependent on perception of wealth. In Thiawor, multiple wives did reside in the same household; some wives migrate between towns and villages depending on the needs or desires of the household. Thiawor has 14 family 
compounds, with multiple households potentially residing within one large compound. Compound systems are in a sense a set of larger communal households of extended family that share resources. Senegalese often live within these types of compounds, which are composed of multiple family units (Randall \& Coast, 2015). Many communities in Senegal have chiefs, with chiefs existing even in urban neighborhoods. In pre-colonial times chiefs held authority based on land control, heritage, and right of conquest; however, chiefs were appointed and regulated during French colonial rule and have been integrated today as an administrative extension and to act as auxiliaries or as relays with governmental heads in the Commune concerning issues in the community. Village chiefs are elected by heads of households within the village (Ribot, 1999). There are also respected elders that hold counsel within the village - in the case of Thiawor, the eldest man and eldest woman hold degrees of respect and concerns would be brought up as a group consultancy with the chief and imam.

\section{Village Wells}

Thiawor receives its water through a network of uncapped, privately-owned hand dug wells located throughout the village. There are no other sources of water available within the village boundaries, although there are existing wells in fields where some animals graze; these are also privately owned. At the time research was conducted, there were 8 wells within the village, of which 5 were considered productive and safe for use. These wells are privately financed, owned, and maintained by families within the village. The head of the household which constructed the well is in charge of financing repairs, maintenance and upkeep, and granting permission for use of the well or water pulling materials. Not every compound allows community members to access a well without bringing their own materials. If a well owner or family is no longer within the village, then the upkeep falls to whomever uses or wants to repair and maintain the abandoned well. This has happened in Thiawor; the well was not used in this test because it was in disrepair. Financing well construction may come from family income through remittances; every compound in Thiawor has a family member who lives or works abroad. As of 2017, remittance inflows to GDP in Senegal was $10.17 \%$ (World Bank, 2019). Senegal, in a 2011 World Bank analysis holds fourth place in Sub-Saharan Africa in total volume of remittances, and fifth place as a percentage of GDP (Mohapatra et al., 2011).

Water is shared and retrieved by each

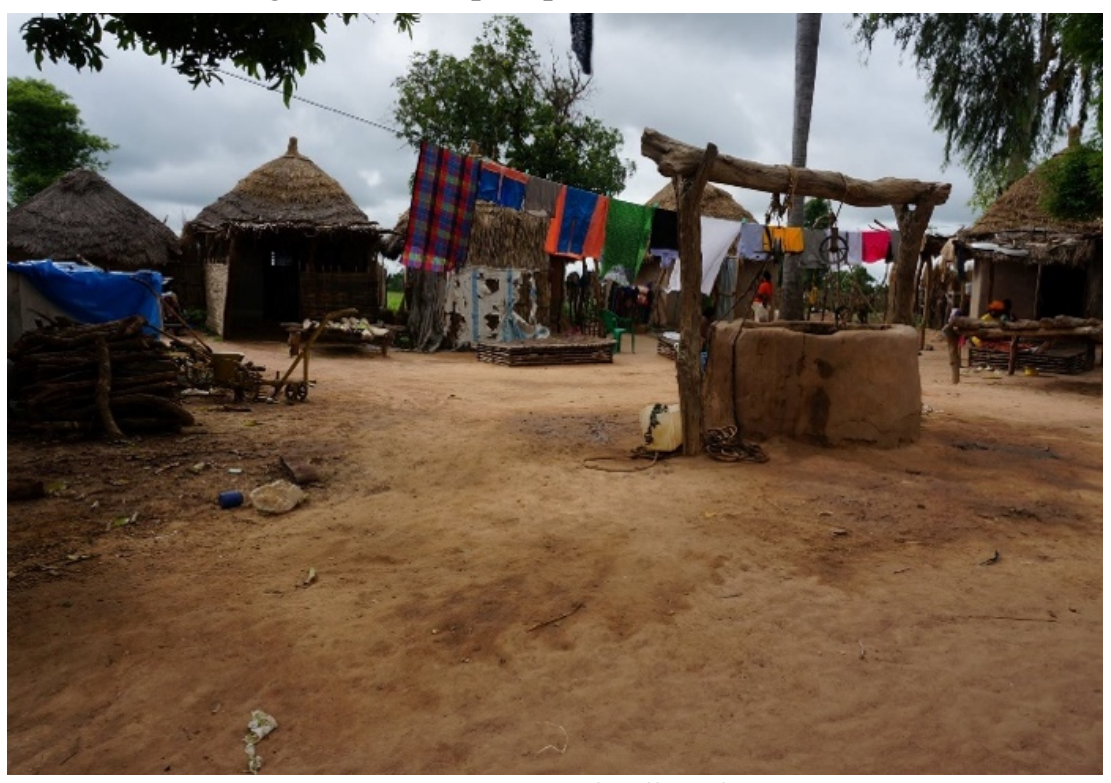

Figure 1: A compound well in Thiawor compound and the households residing within it working together. This makes individual household use difficult to quantify, and so for purposes in this report quantities will be delineated by the 14 identified compounds lying within Thiawor. The method of water retrieval in Thiawor used in the open wells involves pulling on a rope attached to a pulley to draw up a bucket constructed from a plastic oil container. While it is possible to pull up the bucket alone, it is very common to see two or three people pulling on the rope together. The water drawn up together is then split between the pullers based on the amount or size of vessels brought to be filled. If the quantity of water to be pulled exceeds the quantity desired of one puller, continuation of labor is optional for them and the puller may be swapped out for 
another person waiting at the well with their own vessels. Keeping track of labor is determined by the individual and their household or compound duties. No monetary exchanges of labor around the well were observed.

Water wells in Thiawor were dug by professional well diggers using picks, shovels, and buckets. A pick is a common farm tool available to break the surface of the ground, as the soil becomes quite difficult to work. During the rainy season the soil becomes more malleable, even quite muddy during larger rain events. However, due to the work schedule and season, hand-dug wells are repaired, dug, and maintained in the dry season. On projects for local well diggers like compound wells, a lack of tools like motorized pumps that may assist in dredging the wells while working on a well can limit the depth to which wells are dug below the water table. There are no existing irrigation projects for crops or gardens, and there are no motorized or solar pump systems currently within the village.

In recent past there had been exploratory drilling in the area to build a pumped well and a water storage tower; however, engineers miscalculated the depth to the confined aquifer in order to evaluate how deep to drill. This led to major project funding issues, and abandonment ${ }^{1}$. It is speculated that the reason the engineers miscalculated was because they were calculating for the unconfined aquifer, and it was found that the recharge and availability of water would not be able to be sustained by the water tower beyond the confines of one village. The project was supposed to supply 4-5 villages in the area. In Senegal, remittance money is a major source of income in the small villages; villages may fund their own private solutions while they wait for government or international aid groups to step in. Corruption in Senegal and mistrust of the government is high.

\section{Methods and Fieldwork}

The field work of this study applied both hydrological and ethnographic data. This section addresses the methods and field work conducted in the study area for both of these data sets. Goals of the ethnographic field work were to understand water usage qualitatively and quantify daily domestic water use from interviews, as well as determine if there is noted seasonal variation. For the hydrologic research, properties of the aquifer from the bailing of the well were collected.

\section{Pumping Tests}

In the interest of determining the rate at which water is moving through the material comprising the aquifer, a constant-rate pumping test design was developed by bailing the wells using methods outlined by (Shonsey \& Gierke, Quantifying available water supply in rural Mali based on data collected by and from women, 2013). Partnership with local collaborators was necessary in order to successfully gain access and pump water from the well. Teams were created for this purpose in advance of the tests. The hydraulic conductivity $(K)$ - a property to reflect the relative ease with water can flow through a subsurface material - of the aquifer was measured in-situ by performing five manual pumping tests and monitoring recovery in 5 hand-dug, uncapped wells. Each of the five wells was tested once; the tests were performed toward the end of the rainy season, and therefore all results can be

Figure 2: Constructed measurement tape with hollow container to make a sound when reaching the water level.

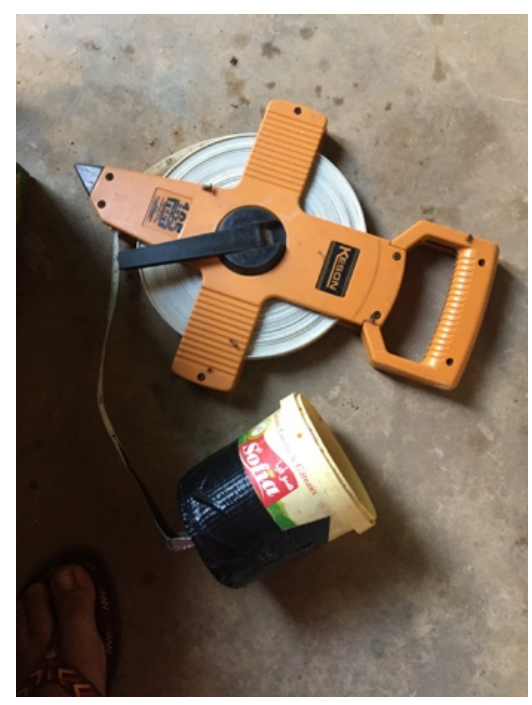
more relevant for rainy-season (best case)

\footnotetext{
${ }^{1}$ This information was provided both anecdotally in conversations established from the author's relationship as a Peace Corps Volunteer, as well as from visits to the abandoned site.
} 
productivities. Wells were tested 8 times in total; 3 of the 5 wells were measured twice due to initial measurement error and material issues.

The wells were chosen for testing based on their spatial distribution throughout the village, the safety and condition of the wells for participant use in the tests, and their ability to provide water during the driest period in the year. The five wells tested were considered the main sources of water for the residents, and the best and most consistent in water availability. Before the commencement of the tests, three additional productive wells in the village were closed off to use due to structural instability, and therefore only five of eight wells were tested.

In preparation for the test, each of the five wells was

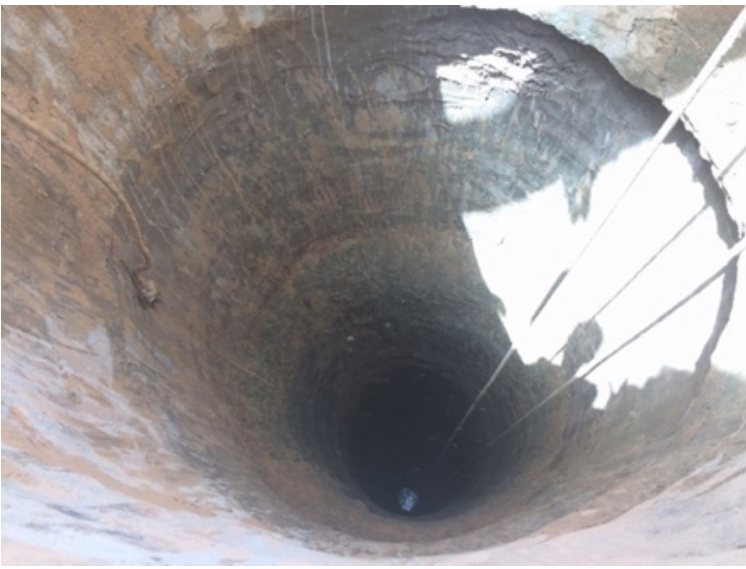

Figure 3: View down a compound well covered to prevent use for approximately ten hours prior to the pumping test to allow water levels in the wells to return to the static (unpumped) levels. Advance approval by the well owners was received for each test, and a large tarp and rope were tied over the rim of the well to prevent use overnight. Individual well tests were conducted over the course of 8 days.

Each morning before a pumping test, the depth to the static water level was measured and recorded. Well diameter and well casing height were taken from measurements of the protruding cement of the well at the top using a tape measure. Ten hours was approximately the longest period of time local residents felt they could go before needs necessitated access to the well. Two pulley systems with attached rope and a plastic oil bucket called a bidong were placed over the well before the test. The

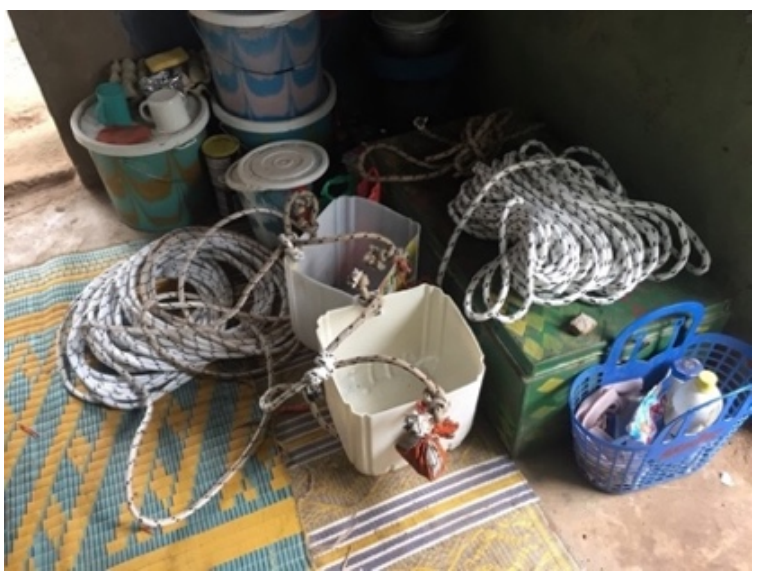

Figure 5: Materials used to pump water from the wells pumping tests were performed by 12 volunteers divided into four teams

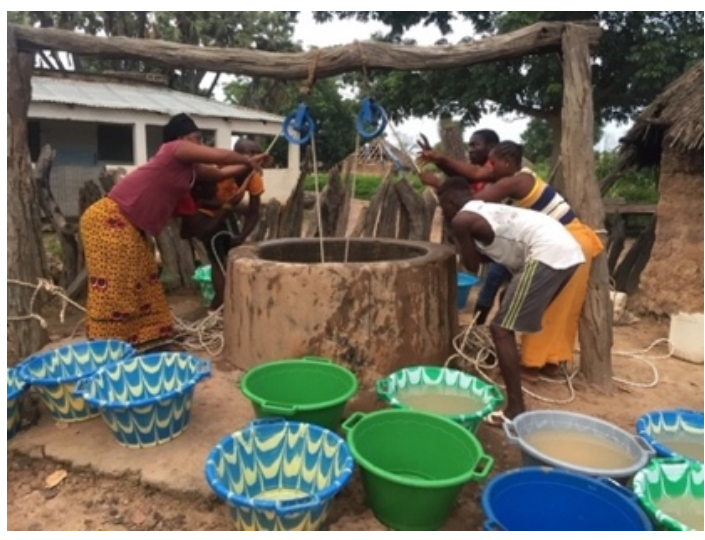

Figure 4: Two teams performing the pump tests at one of the village wells of 3, with two teams pulling simultaneously for 10 minutes on a rope and switching teams for an additional 10 minutes to reach a total of 20 minutes $^{2}$. All team members participated in all five pumping tests. The water was pulled using repurposed plastic oil containers that were attached to rope. These repurposed plastic containers were then pulled over two identical metal pulleys. The water obtained was poured into 30-L plastic laundry buckets adjacent to the well. After the 20-minute pumping period, the contents in the laundry bucket totals were determined to calculate total water volume extracted from the well the pumping rate. This method of water retrieval is the traditionally practiced form in the village and did

\footnotetext{
2 The term "bailing" and "pulling" for purposes of this study are used interchangeably with "pumping," as there are no actual pumps in these wells
} 


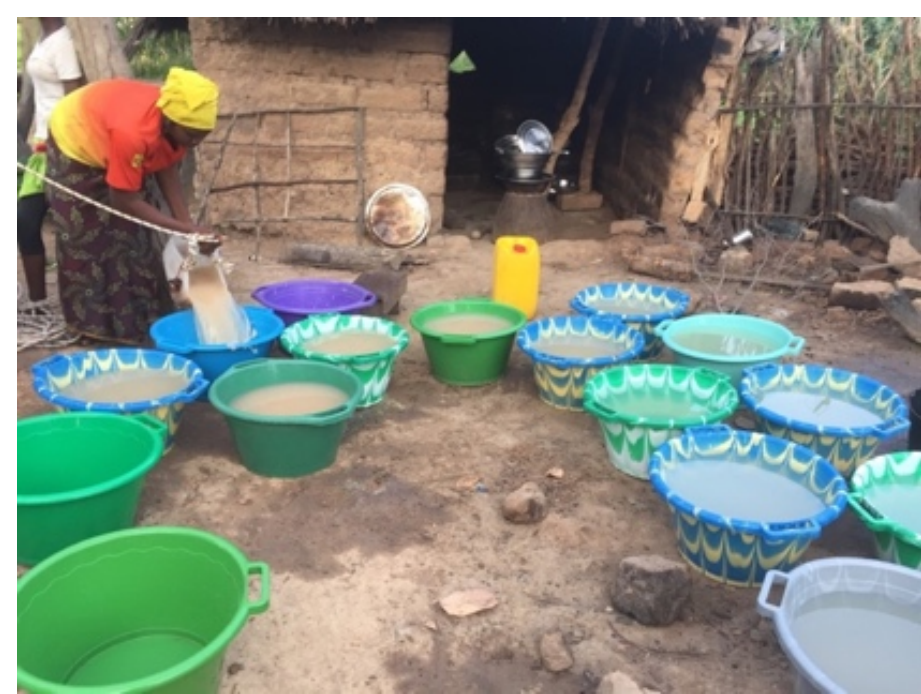

not require any additional learning from participants. At the conclusion of each test, the water in the laundry buckets was distributed amongst assisting team members.

Static water level and the changes in water level over time were measured using a modified bucket method, fashioned with a tape measure and a locally sourced margarine container to use inverted to make a sound when it "hit" the water level in the well. A battery powered water-well "sounder" was originally intended to measure exact depth of the water as the pumping test was conducted; however, it arrived broken and unfixable, so the "sounder" described above was used to Figure 6: Pouring the pumped water into laundry buckets for measurement measure the depth to the water level in the wells. Measurements were taken at regular time intervals at start (time zero) and then after 1, 2, 3, $5,10,15$, and 20-minute intervals. Observation periods lasted up to 595 minutes to fully recharge to static level observed before the pump test. All measurements were done by hand and recorded in field notes. Tests were conducted between 6:15 am and 7:00 am, which is approximately the common time water is pulled in the mornings in the village based on the author's observations. None of the wells were pulled from after the initial morning pump test until the author was finished observing recharge (almost 10 hours after pumping began).

Total volumes bailed were calculated from volumes of laundry buckets collected. Table 1.1 below shows a summary of the test data collected. The water-level-recovery data for each of the wells is displayed in the Results section of this report. After the pumping tests and recovery times and depths were recorded, the information was analyzed with the professional hydrogeology software AQTESOLV (HydroSOLVE, Inc., Reston, VA) to match the existing curves determined from the fieldwork to fit an idealized type curve by modifying the aquifer parameters to fit an estimation of possible aquifer conditions. Using these estimations, an estimation of hydraulic conductivity and idealized maximum yield of the wells may be calculated. This information may be relevant when considering water management systems on a local scale. 
Table 1.1 Pumping Test Data for each Well

\begin{tabular}{|c|c|c|c|c|c|}
\hline Name of Well & Sunkaro & Sankare & Diawara & Danfakha & Camara \\
\hline $\begin{array}{l}\text { Pre-Pumping Rest Duration } \\
\text { (Hr:Min) }\end{array}$ & $10: 15$ & $10: 30$ & $10: 30$ & $11: 00$ & $10: 15$ \\
\hline Height of Casing (cm) & 92 & 74 & 86 & 69 & 67 \\
\hline Width of Inner Well (cm) & 111 & 108 & 118 & 109 & 96.5 \\
\hline Static Water Level Depth (cm) & 3131 & 3140 & 3002 & 3002 & 2990 \\
\hline $\begin{array}{l}\text { Test Duration } \\
\text { (Min:Sec) }\end{array}$ & $12: 30$ & 20:00 & 20:00 & $20: 45$ & 20:00 \\
\hline Volume Bailed (L) & 390 & 930 & 930 & 885 & 840 \\
\hline Pumping Rate (lpm) & 31.2 & 46.5 & 46.5 & 42.6 & 42 \\
\hline Depth of Displacement $(\mathrm{cm})$ & 3162 & $3182 * 3$ & 3050 & 3061 & 3051 \\
\hline
\end{tabular}

\section{Interview Methods}

Qualitative field work was conducted in the village to determine household water usage from the wells that were tested. This section will describe the process and methods used to understand the context of water usage at the local village level.

$3{ }^{*}$ This is an estimation of the water level due to mechanical error at the beginning of the test 
Community members were interviewed for this study addressing seasonal household water use. The study (1317603-1) was approved as exempt on September 24, 2018 by the Michigan Tech University Human Subjects Committee/Institutional Review Board (IRB). This study was performed in addition to geologic data and tests performed at the research site. Submitted to the IRB was the following statement of purpose: "The purpose of this project is to study how local community members in a rural village in Senegal use well water, and what their habits and uses are for domestic and agricultural needs." Local community members were interviewed to understand seasonal and daily water use in the village, including amounts, how it is obtained, and for what purposes it is used for. All of these interviews were audio-recorded and confidential. Names and titles that were revealed during the interviews were concealed using pseudonyms during transcription. Interviewing took place in homes or around wells. Group interviews are considered culturally appropriate, and the researcher received oral consent from all participants.

Participants were found through observation of well activities in the morning; the author monitored morning and evening well activity in all compounds to find interested interview participants that were actively using the wells or those who could recommend someone in the compound. Interviews were conducted at every compound present in the village, and participants were representative of all 23 known households within all 14 compounds. Residential compounds are open air with lots of seating and community members passing through. The questions and oral consent were all provided in the local village language Bambara. Before each interview, environmental observations around the well utilized by each interviewed participant were conducted by the author. Interviews were all conducted after morning or afternoon water retrieval.

The following questions were asked of local residents. The sampling number was picked because it would be representative of the number of compounds in the area. Seventeen questions were asked of participants. Below is an English translation of each of the open-ended questions asked, as well as the introduction observation statement made to initiate the interviews:

"I am going to summarize what I observed today at the well; how much was drawn, how often you came back, how you pulled. I have a few questions to ask about how typical or accurate my observation was"

1.Were my observations at the well typical for your household?

2.When do you or others go to get water for your household? Which water sources? What times of day? How much?

3.How do you get water?

4.Who else comes and uses the wells - e.g., other communities or people who do not reside in town?

5.What are the hottest months typically? Is it always the same every year or does that vary?

6. What month is it hardest to obtain water? Have village wells ever run dry? If so, when does this typically happen?

7.Have there been times of day when the water in the well is not enough for the day? If so, when does this typically happen?

8.Does how your compound obtains water change by season? Explain.

9. What work does the water you obtain do? What uses?

10.How many buckets are filled for your compound when someone goes to get water? How many times a day do you or they get water?

11. What do people do if a well is dry?

12.If someone cannot retrieve water for your compound from the nearest well, what do you do?

13. What is your compound's strategy when you realize there is a problem with the well water? What kind of problems with the water quality and quantity have there been? 
14. What do you do involving agriculture and well water use? Or rephrase: ...Do you use well water for agriculture or gardening? Care for animals? Please describe these activities and about how much water is used for them on a daily (and possibly seasonal) basis?

15.How important is agriculture to this community? Do others use well water for agriculture, gardening, or animal care? If so, same as above.

16. When you or your parents were younger, how did they obtain water? Explain. Did this change by season?

17.When does rainy season start and end? Has this changed from when you were younger?

Audio interviews were recorded using iPhone voice memo and saved to a locked private digital database with restricted access. The interviews were transcribed directly in the local language Bambara from the original audio recordings; care was taken to conceal identities and pseudonyms were used in compliance with IRB. In total, fourteen interviews were conducted, which coincides with the number of compounds within the village. The qualitative analysis software Atlas.ti was used to analyze the interviews conducted in the study. Seventeen codes were created from these interviews; the codes were then used to provide understanding and context of water usage in the village, as well as provide quantitative data of water volume per household.

Interviewees were asked to provide the number of wash basins and or jerry cans they fill for each purpose. An understanding of local water retrieval methods was obtained by having the interviewer describe her observations of methods at the well before the interview, and then asking residents to explain in detail if these observations were typical. In addition, opinions concerning water quality, seasonal water retrieval strategies as well as productive well availability, and seasonal water use were discussed in the interviews. In total, 14 interviews with participants representing every compound in the village were successfully conducted. Interviews lasted for an average of 19 minutes.

\section{RESULTS}

The results section is split into two sections: interview data analysis and pumping tests and analysis in AQTESOLV. Preliminary understanding of seasonal water usage is gauged from these observations and interviews. Localized aquifer and well conditions are estimated from the pumping test data and AQTESOLV analyses.

\section{Interview Data Analysis}

The purpose of this study is to understand domestic water usage at a small village level and understand whether rainy season availability currently meets identified needs. From these interviews, an understanding of conditions around wells in Thiawor are elaborated on specific usage, water retrieval, concerns and informal strategies to deal with issues concerning the wells. While there is slight variation in water allocation depending on agricultural productivity, community members are allocating water to the same five core purposes overall: drinking water, cooking water, washing, watering animals, and gardens. From the quantities allocated to each usage in these interviews, average compound consumption in Thiawor is 540 liters per day, for a total village consumption of 7,560 liters per day.

The water retrieval methods are the same throughout the village; using a metal pulley and rope with a bucket on the end to haul water. There are set times in the day when it is most common to retrieve water - early morning and afternoon specifically, and water labor is split into teams, with water quantity tracked as it is retrieved from the well so that there is a fair distribution of labor. This work distribution results in water depletion of the wells twice daily (mornings and evenings), as well as gatherings of people around the well assisting or waiting for their turn.

Strategies and well etiquette were unexpected findings with regard to dealing with difficulties in the face of water sourcing issues. Seasonal water scarcity was noted from March to June, sand there are a 
variety of strategies implemented around the usage of the various wells in the village. Some strategies include waiting by the wells and pulling small amounts or visiting other neighbors' wells with permission. When water needs to be drawn from wells away from the compound, primarily the next closest is visited, a well is chosen that is less occupied or avoids local drama, and/or donkeys are utilized to assist in the load of pulling and carrying water. There is etiquette involved in the usage of wells; all of the wells are privately owned, but there is an open understanding of shared usage amongst compounds especially because familial ties exist between households. Whether or not materials such as pulleys, rope, and buckets are provided to pull the water from the well depends on the well owner's permission. Water quality concerns were also voiced; the wells are uncapped and unimproved, and as a result often require maintenance when they are contaminated or dry. An understanding of hand dug well maintenance procedures was gained through these interviews. Well choice strategies were also revealed in relation to those maintenance procedures and decommissioning of wells due to water quality concerns.

Overall, daily water needs in the rainy season are considered met by the wells currently in Thiawor. Interviewees mentioned increased numbers of wells at present - eight in Thiawor compared to their past times, when there were only two. But they elaborated that the amount of water available from the two wells in their youth was greater. While there is not enough local data to make any comment about changes in water availability over time, it is of interest that participants actively brought up increased water scarcity compared to their pasts.

This analysis used codes in Atlas.ti to build reports looking for patterns in the interview data to interpret from the interviews. Seventeen codes in total emerged from analysis of the interview data gathered. While not all are discussed in this study, participants particularly focused on Water Quantities, Water Usage Purposes and Allocations, Seasonal Well Usage, Water Retrieval Methods, Water Retrieval Times, Water Scarcity and Well Problems and Remedy Strategies, Well Work Distribution, Water Quality, and Historic Well Usage.

\section{Water Purposes and Allocations}

Domestic water usage purposes as well as daily usage quantities were identified based on purposes identified by each participant from every compound interviewed. The water uses in Thiawor were provided from these interviews to give a broader context of what the situation and implications are for local residents including calculated recharge observations of the actual availability.

The most frequently mentioned purpose of water in the compounds:

- Drinking water, stored in clay vessels in each compound

- Cooking, stored inside or around cooking areas

- Washing clothes, dishes, bathing, cleaning toilet areas

- Watering animals, a seasonally dependent activity for hot and dry season

- Watering the gardens, another seasonally dependent purpose at the end of hot and dry season

Four compounds said that they maintain gardens outside of the major agricultural rainy season. These compound gardens are attached to the main living areas of the compound within the village boundaries and are watered using domestic wells. Compound gardens are an additional nutrition source for many Senegalese farmers, often promoted by NGO projects with the goal of additional household income or increasing local access to fresh nutrient sources. In the interviews conducted, research participants identified whether or not they were doing garden activities and the amount of water they were obtaining for vegetable cultivation. 


\section{Water Quantities}

Results of the village interviews allowed for a quantified calculation of average compound consumption for Thiawor. The best estimates suggest a village population of 386 people $(+/-40){ }^{4}$ Households vary in size, but this population estimate assumes an average compound size of about 27.6 persons. All participants interviewed retrieve their water from the five wells that were tested.

Participants elaborated on the quantities of water that were put toward each household allocation; as a result, an estimate of total usage was able to be found at roughly 540 liters per compound $(+/-240 \mathrm{~L})$, for a total of 7,560 liters per day for the entire village. Consumption volume given from each compound ranged from 300-780 liters per day.

There are 14 family compounds with 5 working wells in Thiawor. Those who maintained a seasonal garden had daily estimates of 90-600 liters of water allocated (an average of $\sim 333 \mathrm{~L}$ ) depending on the scale of production. Only 4 households kept gardens. The daily consumption included all the main purposes listed in interviews. Animal watering is a more seasonal-dependent activity, with demand on the wells to supply more watering needs in the dry and hot season. Each compound on average gives their animals around 170 liters of water a day in the rainy season.

The participants felt they were able to meet their water needs amongst themselves, and rarely do outside villages visit for water needs unless under dire circumstances. No participant mentioned needing to go further than the village for their water needs, but that residents still actively share resources.

"The wells are numerous now, we don't run out of options but people still split everything"

Outside of village boundaries there are two field wells that are used for watering animals and miscellaneous purposes, and transient herders and neighboring villages have been known to visit the wells when theirs have quality issue. Two smaller villages in particular were named, located 1 and 4 kilometers from Thiawor, that have visited compound wells in Thiawor for water needs if their own wells have dried or require maintenance due to water quality. It was mentioned that these villages have even fewer wells than Thiawor.

\section{Water Retrieval Methods}

Water is retrieved using a rope with a simple pulley method and a container such as a plastic cooking oil container to hold water as it is pulled from the well. Participants describe the method as follows:

"If I am pulling, we throw the rope in the well. The rope, not the pulley. I buy the pulley. And the rope, and the tadeau [water container]. And now, if y'all are taking water, you lower the rope using the pulley, after which you pull it a little, three times, until [the water container] is full, after which you pull it [all the way up]...You jiggle it. You will see if it's full."

"You take the end of the rope, you put the end of the rope in the well to pull water...You put the rope in the well to fill it, if it's full you will pull to get it out to put in the laundry bucket"

\section{Water Retrieval Times}

$86 \%$ of the interviewed participants said they pull water twice a day: once in the morning and another in the afternoon. Villagers do not use clocks to keep track of time. "Normal" times of day to retrieve water are delineated by Muslim call-to-prayer "fajiri" (before dawn) and "fitri" or "asr" (afternoon). Villagers pull water after the fajiri-fe call to prayer and before fitri-fe prayer. Approximately $30-40 \%$ of participants said they will increase from twice daily to three times a day depending on the workload and the seasonal need from the compound wells. Only $14 \%$ of participants said their compound

\footnotetext{
${ }^{4}$ Estimates were based off informal anecdotes from conversations with the author and residents
} 
regularly pulls water 3 times a day all year long. When asked to estimate the times they pull water, participants provided similar answers:

"The water times? Water is quick to be taken in the evening, morning. Others do it even the middle of the day, but many people, their needs are early in the morning, and evening."

"When you get up at fajiri time, they get up immediately, five o'clock in the morning, you get up. The mosque, when the mosque is calling they go to the well and get water. After you're done you come home to cook breakfast, then go to the fields."

These times are consistent with what the author observed from her two years as a volunteer in this community. While the actual times would vary, morning water pulling activities did not begin until after the morning call to prayer and began for the second time before the afternoon call to prayer.

\title{
Well Work Distribution
}

Water pulling is generally a community activity; it is easier to complete the task together than separately. The depth of the measured wells was fairly uniform at 30 meters deep and varied less than 1.5 meters. Of water retrieval methods participants say:

\begin{abstract}
"They do it like...they help each other you see. If one has filled their buckets, they also fill others. Well, with pulling, two people is better than one, yes? If one who came to the well and sees another person pulling at the well, it's better to go up and work as two."
\end{abstract}

This gives information as to what some of the strains and needs are of the well. The well needs to provide water for at least two compounds during one pulling activity. The wells are depleted in large chunks, instead of slowly throughout the day as needs arise. Need is therefore (as previously stated in the questions of times of day that compounds need water the most) highly variable, requiring immense effort at a single given moment rather than slowly depleted at a constant rate. It is important to understand the times at which the well is most stressed upon by residents needing to obtain water; this will give a better portrayal of in what ways and lengths of time and gaps in time the well is and is not in use.

\section{Seasonal Well Usage}

All of the participants reported water insecurity and water demand issues. All reported insecurity and scarcity during the hot and dry period that precedes the rainy season and is after harvesting is finished. Those that were able to give dates noted the months of March through June as the most difficult months to get enough water from the wells. They also reported that this is the time of year in which wells go dry the most frequently. May, then April, then June had the highest number of mentions. One of the five wells that were tested was reported as being unable to meet household demands year-round. 
All participants were able to describe water scarcity in relation to their agricultural calendar. On water insecurity, one participant noted:

"In the rainy reason, we receive water. Rainy season finds the wells full and it gives a lot of water. But in the hot season, when it's really hot and you're pulling often, the well is dry."

Participants feel their need for water increases during the dry hot season. There is demand for larger quantities of water allocated to animal watering that does not exist during the rainy season, when extra water can be provided to the animals through roof-rainwater catchment, moisture in plants and grasses, or surface water. On the change in animal activity and burden on the wells, participants said, for example:

"No, in the hot season... hot season you'll find it quite hot. They give water two times a day. But in the rainy season, one time. Yes, it's cold and the animals don't tire and there's lot of green grass to eat."

"Getting water in the rainy season is easier than in the dry. The well in the rainy season may be dirty but it doesn't dry. But in the dry season the wells are dry and you'll find people have dug deeper so there is water. People, donkeys and horses drink a lot."

While water needs for animals may vary seasonally and can be amended by alternative sources in the rainy season, also of note were the strategies that villagers utilize to ensure they have sourced enough water for their needs.

\section{Water Scarcity, Well Problems and Remedy Strategies}

Another part of this analysis was to understand village perceptions of the wells' productivities in relation to their domestic needs and the demand on the wells. The author sought to understand if locals felt the current well situation was plentiful, lacking, and/or seasonally dependent. Overall, participants felt that the rainy season offered plentiful water, but that there is an extra demand on the wells in the dry season in addition to a lack of availability. All participants said they wait around while the wells refill; those that offered time estimates ( 3 participants) said they can get some water after around a one-hour wait time in the dry season. Expanding about this wait time for water collection, 9 participants said they are able to get less than 5 laundry buckets with a 30-liter capacity (30 liters each for a total of 150 liters), but 5 participants specified between 2-3 laundry buckets, or 60-90 liters, for themselves. It should be noted that the pumping tests were performed at the end of the rainy season. The recharge data collected cannot reflect the water situation of the dry season, only the peak performance of the wells at the end of the rainy season. Of residents' strategies to deal with water scarcity:

"If the well is refusing to give water, we leave it. People come sit under a tree, and leave it alone. They leave it for... an hour or two, and that's when water has filled again. Then they pull water."

"The well didn't used to be deep like it is now. It wasn't far like now, but back then there was more water than now."

"We get water in our compound, and if the well is dry we wait until it has made more water. After, we go and we look at it again and we pull a little. We find its made a little and we'll take that."

"If water used to be there we wait and it'll recharge, and we pull again. You have to be patient until it recharges."

"If you've pulled a little water, the well dries up. You pull only a little, and what water you have you split." 
While all compound wells are privately owned, there is agreement for shared usage of wells. Familial ties and intermarriage between compounds are common. Wells are expensive to dig, and in Thiawor there can be up to 8 working wells for 23 households (14 compounds) under the best circumstances. As a result, not every compound has equal access to a well even if all are operational. Usage of materials like pulleys, buckets and rope may be brought by outside households depending on the will of the well owner.

"There are some well owners, you see, there's a lot of people using the well and pulley and they don't say anything. Even let others use their rope. But there are others, they bring their own rope. We let them use our pulley. But there are other [well owners], they say something and you bring your own rope. They say this so their own ropes will not break."

There are lots of strategies in place to determine which well to use depending on what the issue is; for example, dry season wells or wells that have not yet been addressed for maintenance may be temporarily out of order, and so families may redirect water sourcing from other wells that are closest by. One well in particular is known to have poor water quality and is only used for washing clothes and watering animals.

"Even in hot season, sometimes water is here [in our well]. Right now, water isn't in the well. [Our neighbor's] well water is bad, so they sometimes come here. They wash their clothes from their own well, but they have to let it sit in the bucket a while, their water is really bad."

"When there are too many people at one well, sometimes [a household from across the village] will come here. If they've found their closest well dried, they will look and go to the next closest"

Donkeys and horses can also be appropriated for water-pulling, although this is often reserved for their own drinking water or if children are out of school and sent to retrieve. Some households have access to donkeys and horse carts, while others must borrow. This also plays a factor into distance and time spent pulling water and which well is chosen to draw water from as a result. Another factor in well usage is local politics and crowding. If one well is currently occupied with a long wait time, those in need will often visit another less-populated well to retrieve water even if it is farther away from their compound. One participant mentioned 6 households that at various times retrieve water from their well. Fighting and disputes occurring within a compound can also result in temporary avoidance of particular wells.

"If a lot of people have gathered, their gossip also increases. And if bad words increase even more people come. You know at times people are fighting so much. Then the whole village comes out."

Despite these strategies that are implemented to ensure the quantity of water necessary for daily demands is met, water quality is an additional stressor to water security that emerged as a concern in these interviews.

\section{Water Quality}

All the wells in Thiawor are unimproved and unprotected. General water quality issues that were mentioned concerned included the drying of the wells, lack of clarity of the water, organisms falling into the well such as birds, toads, bugs and lizards, snakes, leaves, smelly water, and dust from seasonal dust storms, or the abandonment of wells due to lack of owner maintenance. Many participants' order of operations in response to these issues was to wait it out or pull from another well, dig out any sediment from the bottom of the well and then bleach the water, strain water with cloth over drinking vessels, wash out their own buckets first, and then finally resurface the well walls with fresh mortar. 


\section{Historic Well Usage}

To understand the duration in which this pulley method has been in existence in Thiawor, historic water retrieval methods were asked of interviewees. The purpose of this question was to learn what has changed over time. Nearly $80 \%$ of the participants reported having used a pulley method of water retrieval in their youth, and mention that pulley quantity has increased since they were young. Five mentioned pulling with rope and tree branches without a pulley, but two of them mentioned this as conditional if the pulley broke. Seven stated that there used to be fewer wells in the village, and since their youth more wells have been dug within the village boundaries. However, when the two wells existed in the village, it was plenty for all compounds to receive their water without waiting. Seven compounds used to maintain gardens compared to four at present. Seven also mentioned that pulley materials have improved over time. More metal pulleys are available at the wells, but the actual amount of time using the pulleys have increased over time. Two separate participants mentioned the well water levels of the area dropping 8-10 meters in the last 60 years. These participants were involved in contracting or assisting well maintenance in the village and have a reliable knowledge and history of the area. The quote below highlights the notable change from a participant in the discovery of the depth added to the well:

"A long time ago, people had dug a well to claim a garden. After, [my brother] came and wanted to dig again there. He dug another 8 meters to get to water in that well. It was like, 60 years ago the well was first dug. It hit water, and now the times are, if you want to find water you dig deeper past that mark."

The findings in this project conclude that daily domestic water needs are met in the rainy season, and that average compound use for a compound of approximately 27.6 persons use 540 liters-per-day. Five main uses of domestic water were identified for drinking, cooking, washing \& bathroom needs, animals, and garden watering. Water retrieval methods from the well are identical throughout the village; all use the bucket-pulley method to source water, and $86 \%$ retrieve water twice a day with the remaining $14 \%$ three times a day. Participants all noted water insecurity, but especially in the dry season as it requires more need for animals and gardens and drinking water. Animals may at times be used draw their own drinking water but are not used for household water sourcing. Rainy season availability was enough to satisfy domestic purposes overall, but there is a decline in gardening despite a $300 \%$ increase in wells placed through the village compared to historic recollection. Additionally, while there are more wells and the materials to retrieval water have improved, the water table has lowered, which directly impacts the amount of energy expended in order to source water using the same bucket-pulley method that has been traditionally used in the village. Of interest were the elaboration on a variety of strategies to deal with difficulties in the face of water sourcing issues; participants will share well usage and labor together, and patiently wait while the wells recharge to continue filling the containers. If waiting is not an option, they will then choose certain wells depending on distance to the home compound, water quality, and social friction.

\section{Pumping Test Results and Data Analysis Using AQTESOLV}

Recovery tests were performed in 5 wells, using methods similar to a study in Mali performed by Cara Shonsey (Shonsey \& Gierke, Quantifying available water supply in rural Mali based on data collected by and from women, 2013). In an in-depth analysis, Shonsey used interviews as well as AQTESOLV and MODFLOW to characterize and understand water usage and aquifer properties.

The average volume taken from each of the five pump tests was over 800 liters, or 42 liters per minute over the 20-minute pump test. One of the five wells was emptied within 12.5 minutes of starting the pump test. Observations during recoveries ranged from 2-10 hours until reaching static level prior to pumping. The full fieldwork observations for each well are provided in Table 1.1. 
Understanding hydrologic conditions in the aquifer was approximated using aquifer analysis software. The five sets of recovery data obtained through this field method were analyzed using the software program AQTESOLV. This software allows for analysis of wells in confined, unconfined, leaky, and fractured aquifers, and offers tailored solutions based on well conditions. Hydraulic properties like transmissivity and hydraulic conductivity were estimated from data collected.

Because it is nearly impossible to achieve a constant pumping rate while bailing (pulling) a well, the recovery data was analyzed because that analysis does not require a constant rate (see (Shonsey \& Gierke, Quantifying available water supply in rural Mali based on data collected by and from women, 2013)). From recommendations in AQTESOLV, solutions from Moench (1997) and Dougherty-Babu (1984) were deemed the most suitable considering site conditions and data collected (Moench A. F., 1998) (Dougherty \& Babu, 1984). The program identified these two solutions for situations with wellbore storage, partial penetration in the aquifer and recovery data.

Moench (1997) derived a mathematical solution for unsteady flow to a partially penetrating, finite-diameter well in a homogeneous, anisotropic unconfined aquifer with delayed gravity response. This solution also includes corrections for delayed observation well response (Moench, 1998). Of suggested solutions, Moench (1997) provided the best fit and match of input data requirements based on information available. All of the wells were matched visually to determine the best fit. Manual parameter adjustments are performed with the "tweaking" tool in AQTESOLV so that the solution better matched the data from the pumping tests.

Well condition parameters were measured to perform analysis. All the wells were assumed vertical and partially penetrating. Parameters estimated and the methods used are as follows: The well radius $\left(r_{w}, \mathrm{~cm}\right)$ of the wells below the cement "casing" was estimated visually by the author, as it could not be measured safely without going down the well itself. The casing radius $\left(r_{\mathrm{c}}, \mathrm{cm}\right)$ was also estimated by the author, but it must be taken into account the inside diameters vary in depth and are not perfect cylinders. The saturated thickness $(b, \mathrm{~cm})$ refers to the approximate depth of the water in the well before pumping; this was estimated at 1 meter by the author (see Site Location). Other parameters $\left(T, S, S_{y}\right)$ were determined using the fit with AQTESOLV. Transmissivity $\left(T, \mathrm{~cm}^{2} / \mathrm{min}\right)$ is the rate water flows through the aquifer and is the most sensitive and important parameter in well productivity analysis. Storativity $(S)$ is the volume of water per unit surface area released from storage in the aquifer per unit decrease in hydraulic head. The groundwater when first released from storage behaves similar to that of a confined aquifer; or an early phase in delayed yield of an unconfined aquifer due to the water being stored in the well being drained. The specific yield $\left(S_{y}\right)$ refers to the ratio of water yield under gravity to total volume in the case of unconfined aquifers. The specific yield estimated from the fit of AQTESOLV behaves as unconfined with a delayed yield. Wellbore Skin Factor $\left(S_{w}\right)$ while allowed in the Moench (1997) solution to take into account for a zone where hydraulic conductivity around the well is lower than the formation itself-was not considered because it was not sensitive to the fit of the solution, and because of the manual pumping and uncertainties in other measured parameters like well radius.

Table 2.1 below displays estimated parameter values obtained using AQTESOLV. Each logged point of recovery along with its corresponding time stamp were input into AQTESOLV after the conclusion of the pumping test. Each of the five sets of recovery data was fit using the Moench (1997) solution within the AQTESOLV software. 
Table 2.1 Parameter values of each well derived from Moench (1997) solution

\begin{tabular}{|c|c|c|c|c|c|}
\hline \multirow[t]{2}{*}{ Parameter } & \multicolumn{5}{|c|}{ Thiawor, Senegal, Well Name } \\
\hline & Sunkaro & Sankare & Diawara & Danfakha & Camara \\
\hline Transmissivity $\left(T, \mathrm{~cm}^{2} / \mathrm{min}\right)$ & 730 & 380 & 430 & 5300 & 130 \\
\hline Storativity $(S)$ & 0.1 & 0.008 & 0.001 & 0.1 & 0.04 \\
\hline Specific Yield $\left(S_{y}\right)$ & 0.10 & 0.19 & 0.10 & 0.27 & 0.13 \\
\hline Well Radius $\left(r_{w}, \mathrm{~cm}\right)$ & 90 & 131 & 100 & 383 & 73 \\
\hline Casing Radius $\left(r_{c}, \mathrm{~cm}\right)$ & 60 & 80 & 72 & 195 & 63 \\
\hline Wellbore skin factor $\left(S_{w}\right)$ & 0.37 & 0.23 & 0.08 & 0.6 & 0.08 \\
\hline Saturated Thickness $(b, \mathrm{~cm})$ & 100 & 100 & 100 & 100 & 100 \\
\hline $\begin{array}{l}\text { Hydraulic Conductivity ( } K \text {, } \\
\text { cm/min) }\end{array}$ & 7.3 & 3.8 & 4.3 & 53 & 1.3 \\
\hline
\end{tabular}

Hydraulic conductivity $K$ was estimated using Darcy's law, using transmissivity values gained from visual curve matching, and an estimation of saturated thickness $(b)$ as $100 \mathrm{~cm}$ made based off best field estimates and conversations with local well diggers about the wells. Representative values of materials as outlined by Domenico \& Schwartz (1990) in all five wells suggest that they are fine to coarse grain sand materials, and four of five $K$ values are very consistent with one another and may be recharged from the same aquifer. While groundwater flow in the area was not measured using a traditional pumping test to compare results, the values drawn from the graphs solutions show that there is consistency in hydraulic conductivity representative values gained from the tests. The recovery curves fit to the Moench (1997) solution may be viewed in the following pages. 


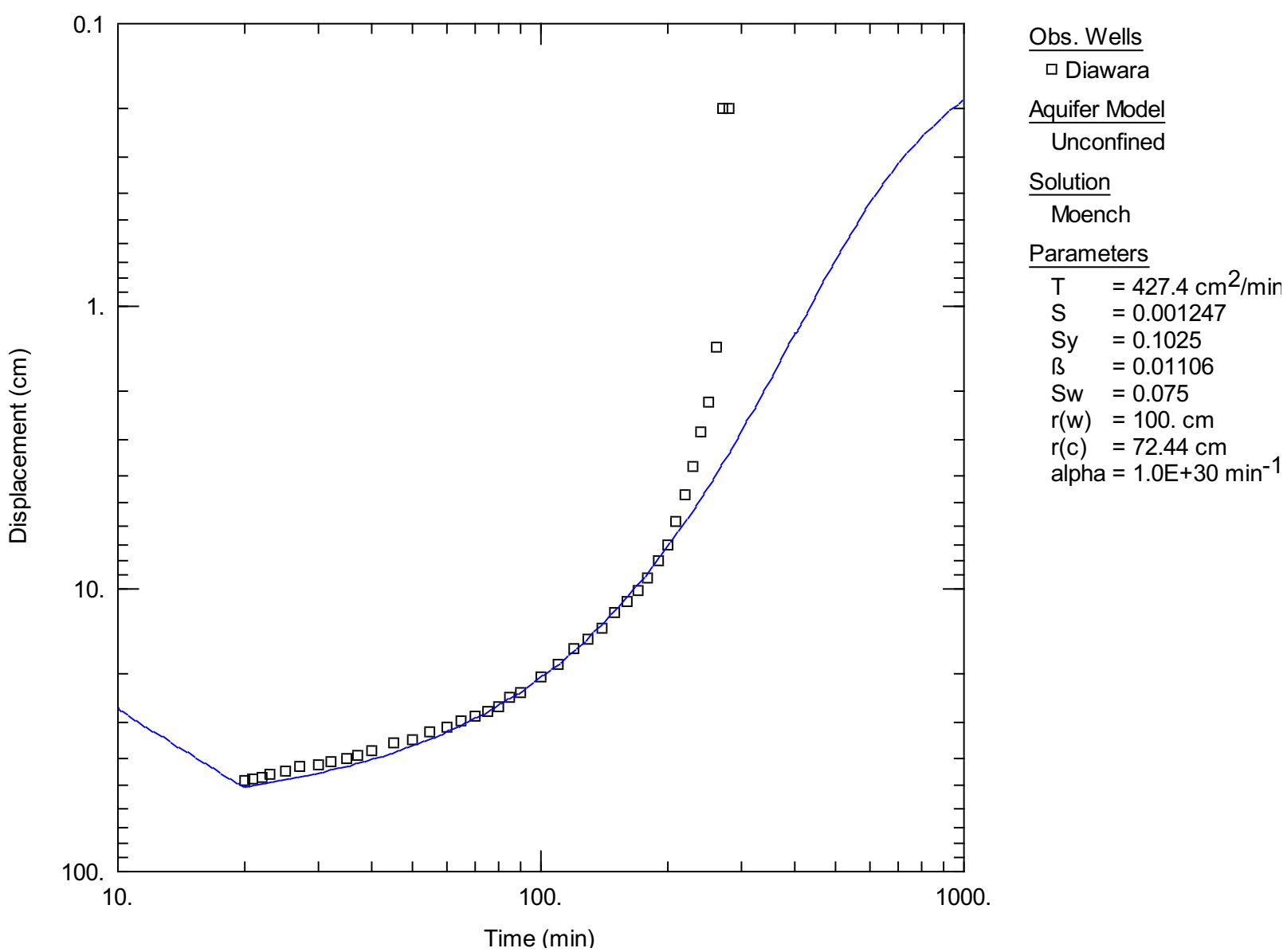

Figure 8: Diawara Well recovery phase of pumping test. Data fit with AQTESOLV to match parameters to the Moench (1997) solution, which accounts for pumping and recovery in a partially penetrating well with wellbore storage in a homogeneous, isotropic, unconfined aquifer. 


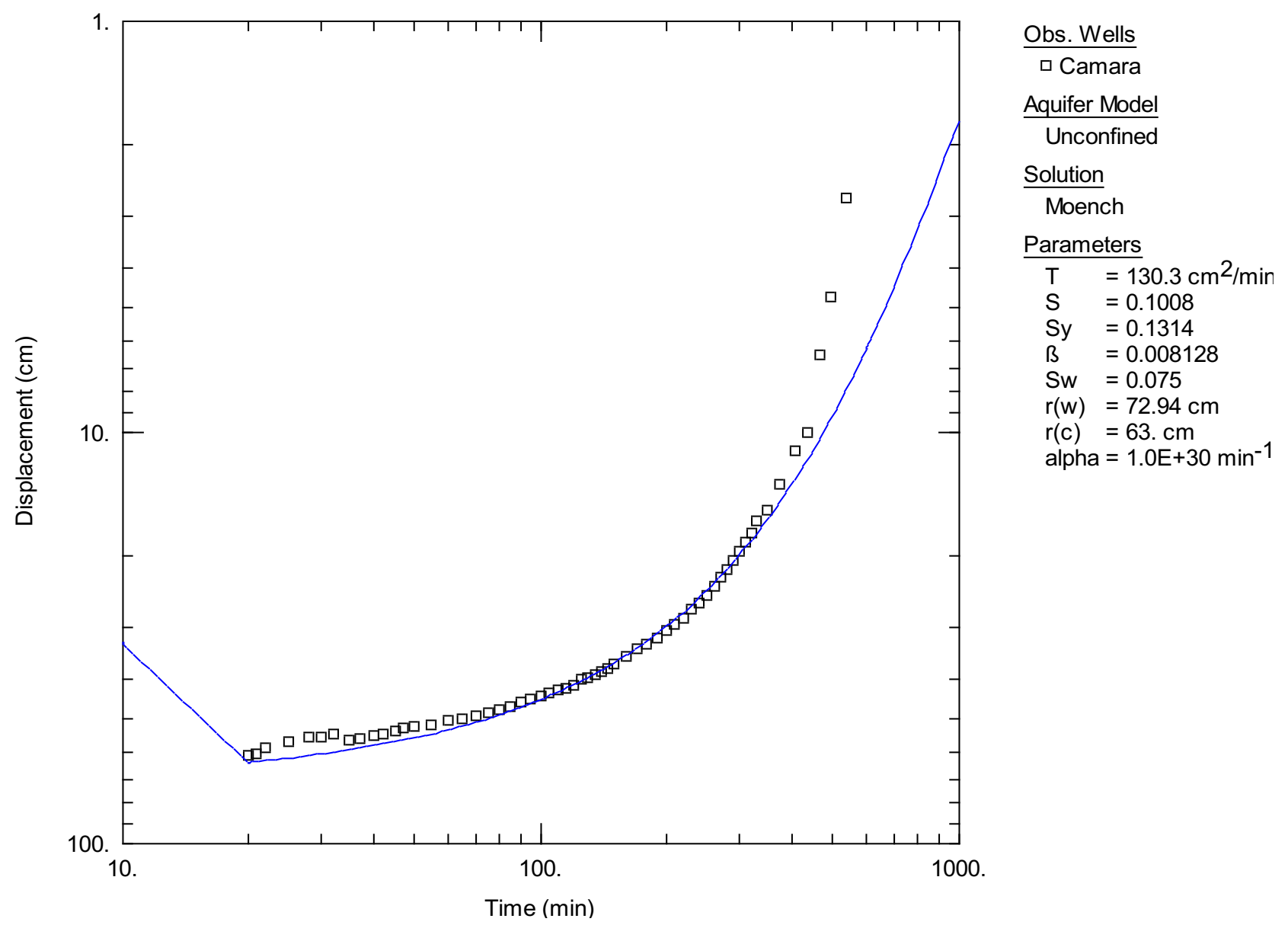

Figure 9: Camara Well recovery phase of pumping test. Data fit with AQTESOLV to match parameters to the Moench (1997) solution, which accounts for pumping and recovery in a partially penetrating well with wellbore storage in a homogeneous, isotropic, unconfined aquifer. 


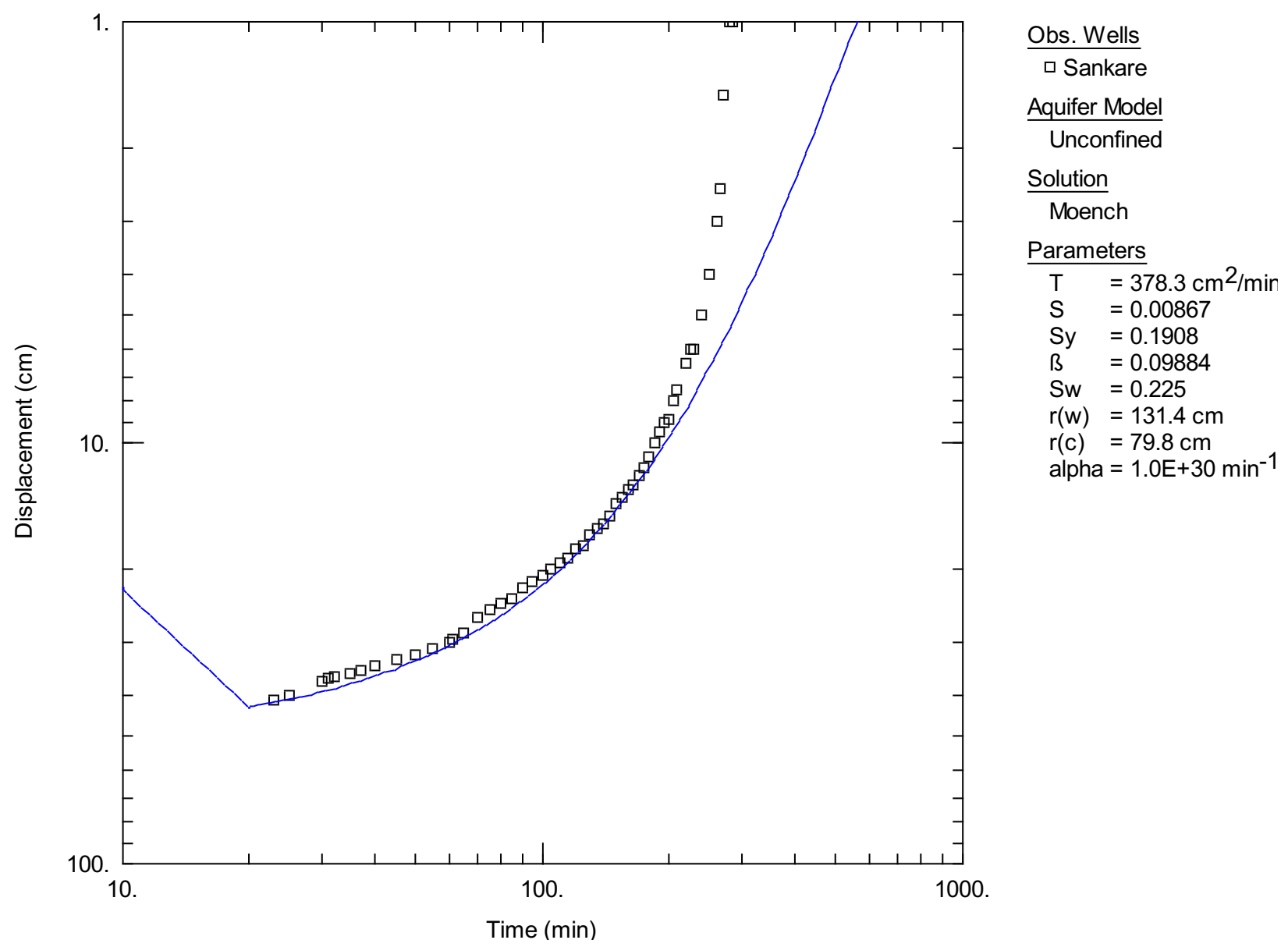

Figure 10: Sankare Well recovery phase of pumping test. Data fit with AQTESOLV to match parameters to the Moench (1997) solution, which accounts for pumping and recovery in a partially penetrating well with wellbore storage in a homogeneous, isotropic, unconfined aquifer. 


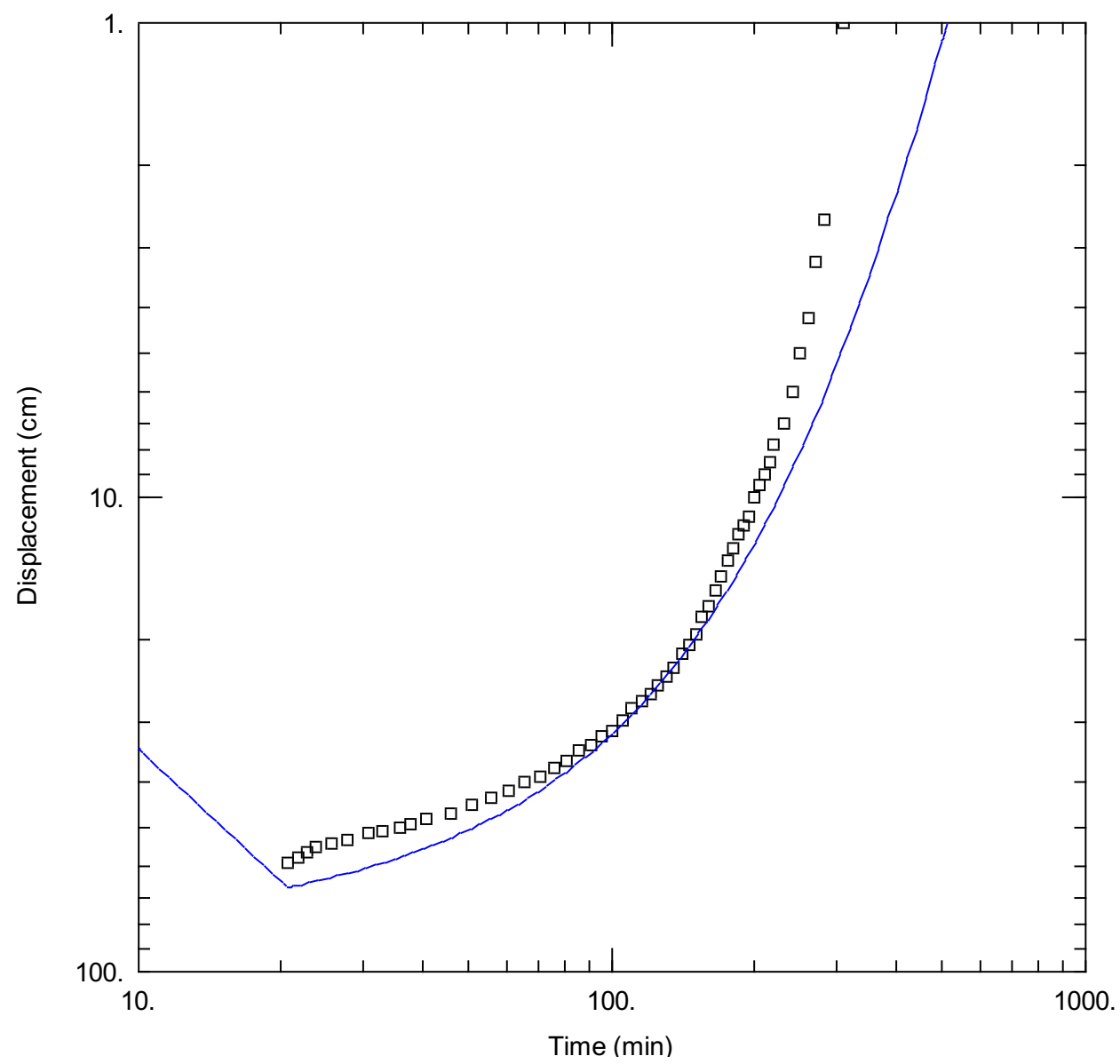

Obs. Wells

口 Danfakha

Aquifer Model

Unconfined

Solution

Moench

\section{Parameters}

$\mathrm{T}=5343.9 \mathrm{~cm}^{2} / \mathrm{mir}$

$\mathrm{S}=0.1006$

Sy $=0.2771$

$B=0.01453$

$\mathrm{SW}=0.6$

$\mathrm{r}(\mathrm{w})=383.4 \mathrm{~cm}$

$\mathrm{r}(\mathrm{c})=195.1 \mathrm{~cm}$

alpha $=1.0 \mathrm{E}+30 \mathrm{~min}^{-1}$

Figure 11: Danfakha Well recovery phase of pumping test. Data fit with AQTESOLV to match parameters to the Moench (1997) solution, which accounts for pumping and recovery in a partially penetrating well with wellbore storage in a homogeneous, isotropic, unconfined aquifer. 


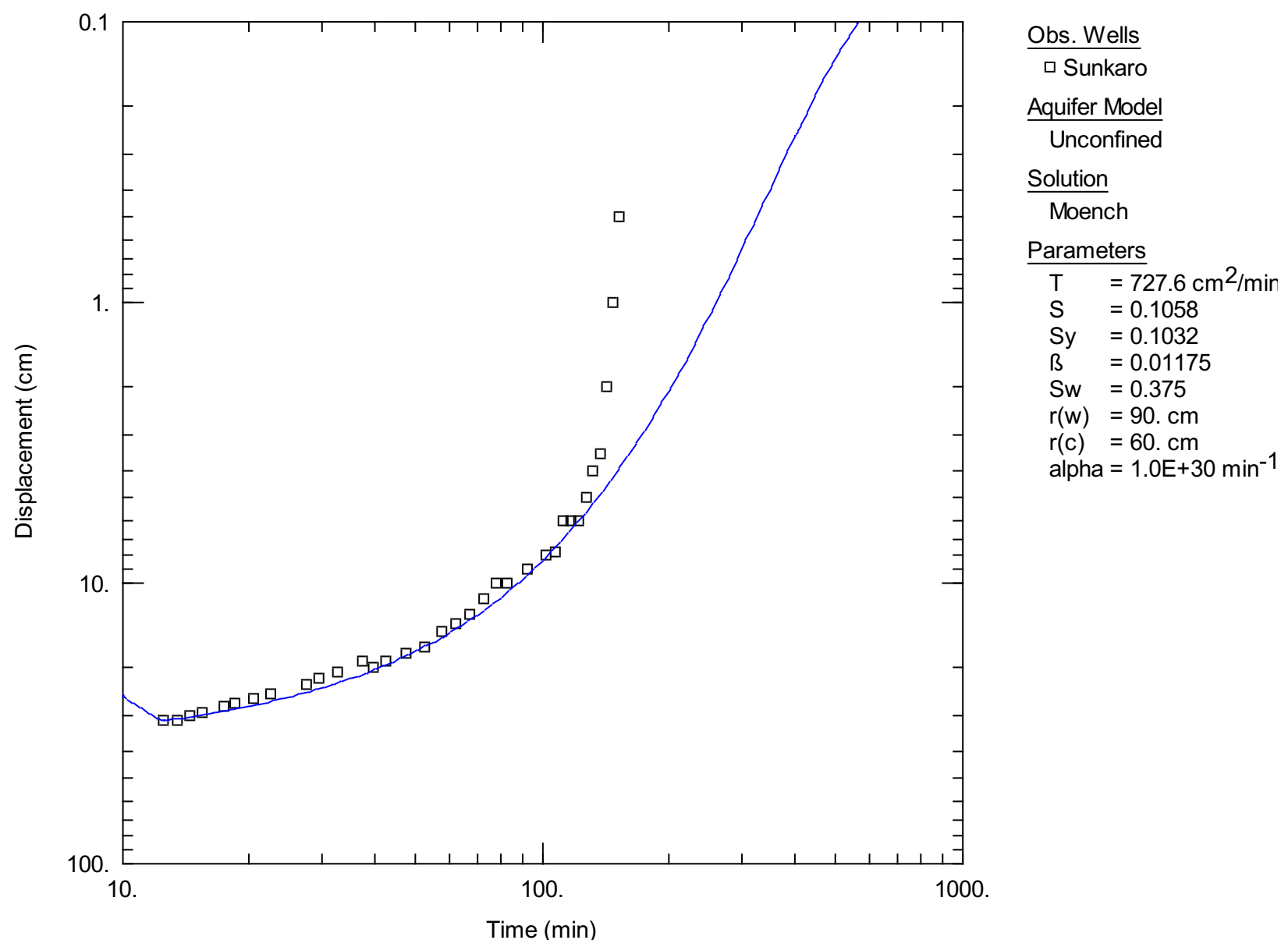

Figure 12: Sunkaro Well recovery phase of pumping test. Data fit with AQTESOLV to match parameters to the Moench (1997) solution, which accounts for pumping and recovery in a partially penetrating well with wellbore storage in a homogeneous, isotropic, unconfined aquifer. 


\section{Pumping Thiawor Wells at Equilibrium}

The percentage of maximum yield was calculated using discharge and percent drawdown to understand how efficiently the wells may be pumped in idealized aquifer conditions as compiled in Table 3.1. Parameters previously described to calculate this include flowrate $(Q, 1 \mathrm{pm})$, saturated thickness of the formation $(b, \mathrm{~cm})$, transmissivity $\left(T, \mathrm{~m}^{2} / \mathrm{s}\right)$, and drawdown $\left(s_{w}, \mathrm{~cm}\right)$.

Using the Thiem solution for unconfined flow, idealized unconfined well hydraulics may be estimated. Idealized conditions in this instance refers to a homogeneous, isotropic aquifer without boundaries (Sterrett, 2007). The boundary assumption is valid if the effects of pumping does not propagate to an actual boundary over the duration of the test, a condition that is likely valid over the small volume pumped and short duration of the test. The assumptions of homogeneity and isotropy are inherent in the experimental approach that was used, where observations were obtained in only the pumping well. Observations at other locations obtained simultaneously would be needed to observe spatial dependencies on the aquifer properties.

Table 3.1 Percent drawdown and estimated percent maximum yield of wells

\begin{tabular}{|l|c|c|c|c|}
\hline Well Name & Sankare & Diawara & Danfakha & Camara \\
\hline Saturated Depth of Aquifer $(b, \mathrm{~cm})$ & 100 & 100 & 100 & 100 \\
\hline Relative Drawdown $\left(s_{w} / b\right)$ & $41 \%$ & $48 \%$ & $59 \%$ & $62 \%$ \\
\hline Flow Rate $Q(\mathrm{lpm})$ & 46 & 46 & 43 & 42 \\
\hline Specific Capacity, $Q / s_{w}(\mathrm{lpm} / \mathrm{cm})$ & 1.1 & 0.95 & 0.72 & 0.68 \\
\hline$Q_{\max }(\mathrm{lpm})$ & 72 & 62 & 51 & 49 \\
\hline$Q / Q_{\max }$ & $65 \%$ & $75 \%$ & $83 \%$ & $85 \%$ \\
\hline
\end{tabular}

During the pumping test, the Diawara well was pumped at $46.5 \mathrm{lpm}$ for $50 \%$ drawdown, which corresponds to a 75\% maximum yield (Sterrett, 2007). The maximum pumping rate $Q_{\max }$ of $62 \mathrm{lpm}$ corresponds to $100 \%$ drawdown in the well, which is impractical, considering the current form of water retrieval in the village. To achieve more flow, the well would need to be deepened and more tests conducted for the deeper configuration.

As with the Diawara well, remaining wells were compared to hypothetical $100 \%$ drawdown. The Danfakha well was pumped at $42.6 \mathrm{lpm}$ for $59 \%$ drawdown, corresponding to an $83 \%$ maximum yield. The maximum pumping rate to reach an ideal $100 \%$ yield is $51 \mathrm{lpm}$. The Sankare well was pumped at $46.5 \mathrm{lpm}$ for $41 \%$ drawdown, corresponding to a $65 \%$ maximum yield. A maximum pumping rate of 72 $\mathrm{lpm}$ is needed for $100 \%$ ideal yield. The Camara well was pumped at $42 \mathrm{lpm}$ for $62 \%$ drawdown, with an $85 \%$ maximum yield. This means the Camara well would reach $100 \%$ yield at a maximum pumping rate of $49 \mathrm{lpm}$. The Sunkaro well could not maintain the pumping rate used to draw the well down during the tests, so that rate is beyond the maximum. The other 4 wells, however, were able to sustain the rates and so those could be used to forecast maximum pumping rates for the current well configurations. 


\section{Discussion}

\section{Pumping Test and Analysis Discussion}

The recovery data is limited to one set of measurements over a one-week time span. The tests themselves may involve human error, as resident participation in conducting the tests was a necessity. Team members mimicked the action of a pump to bail out the well, and so incongruences in collected data may be a result of human error. Additionally, materials were sourced locally to conduct the test, and may lack precision and quality. This study was conducted solely during the rainy season; comments or recommendations regarding water scarcity or management systems outside of the rainy season are difficult to claim. A dry season test was unable to be conducted due to limitations of the author's stay as a Peace Corps Volunteer.

AQTESOLV analysis involved the assumption of a constant pump rate; however, in the field there is potential for inconstancy due to the reliance on a manual pulling method. Additionally, some estimations in the software needed to be made; the depths of the well screen were unable to be measured, and so estimations based on local knowledge of well-digger perceptions and conventions were made to assume 1 meter of water saturation. Village wells are often maintained during the dry season when water levels are lower, so it is likely this depth of water saturation is a safe but inaccurate estimation. It is also unknown if the pumping test performed in Thiawor significantly affected surrounding well depths, as they were not measured in this process nor mentioned during interviews.

Examples of similar studies have been performed with manual pumping tests from Shonsey (2013) and Gross (2008). Shonsey (2009) conducted fieldwork in Mali using both interviews and multiseason data to model groundwater conditions and local water use. In both Gross (2008) and Shonsey \& Gierke (2013) work, they noted that recovery curve analysis may be the best method to determine hydraulic conductivity. Myre (2008) expanded further on the pumping test solution analyses of Gross's work to compare analysis solutions using AQTESOLV. In Myre (2008) expands on Gross (2008) thesis and analyzes casing storage in relation to her hand pumping tests in Nicaragua. Similar to Thiawor, pumping tests were conducted to determine hydraulic conductivity and transmissivity of an area surrounding the wells. Drawdown during the Thiawor pumping tests ranged from 31 to $61.5 \mathrm{~cm}$, representing mostly casing storage in the wells (Myre, 2008). Casing storage is the water in the well prior to pumping. In normal drilled wells, casing storage is negligible due to the narrow diameter of the well casing. However, in the case of hand-dug wells like Thiawor, casing storage is important because the quantity of water that must be removed from the wells during pumping is not representative of discharge in the well.

Myre (2008) outlines assumptions of analytical aquifer analysis for confined aquifers, but mathematically the behavior is identical in unconfined as long as drawdown is under $10 \%$ of the saturated depth of the aquifer (Gierke et al., 2008). In all but the Sunkaro AQTESOLV analysis, the transmissivities estimated from visual curve matching were similar to one another, suggesting a consistency in aquifer material for all tested wells - unconsolidated sedimentary material: fine to coarse grain sand.

The visual curve matching requires fitting the recovery data to that of an ideal recovery curve. Ideal recovery curves should slow down, as depicted in the ideal curves fitted to the data points collected (See Results). All wells demonstrate a similar discrepancy of increasing rate of recharge at the top of the curve. This discrepancy may be due to seepage; however, without further investigation it is difficult to discuss.

Hand-dug wells with depths less than 50 meters are frequently recharged from the water table. The lack of full multi-season pump test data set makes it difficult to draw conclusions about water scarcity or availability in the dry season in Thiawor. However, it may be argued that the discussion of water scarcity present even in the rainy and productive season suggests that it is a growing problem even within a productive time of year. With the interviews it cannot be stated that climate change is the factor of these 
wells going dry, but regional rainfall trends in West Africa suggest that a decrease in rainfall or less predictable or regular rainfall events could result in insecurity of water available due to the nature of the wells and their recharge method (Grace et al., 2018). Increasing rainfall unpredictability, in addition to projected rapid population increase of approximately 2.8\% (The World Factbook, 2019) has potential to lead to domestic water use issues relating to management of households or demand and allocation of water in the future. Senegal has a history of drought, and projections of future variation and unpredictability have been made. Since impacts of a drought on groundwater levels lags behind the failure of rains and surface water runoff (which in turn is associated with reduction in groundwater recharge), small rural communities like Thiawor may be adversely affected by drought in the future and not have a way of planning or mitigating this issue (Foster et al., 2006) Sourcing a motorized pump to assist with deepening of the wells during the dry season may increase the saturated depth of the wells that could in turn increase the yield of these wells. Any newly constructed wells in the village with this method could still easily be placed within the confines of the village or next to existing wells, due to the relatively low pumping rates of community members using the rope and pulley method of drawing water. Constructing a newer well in close proximity to existing older wells would have negligible potential for well interference.

There is currently no rainwater storage, nor deeper drilled or pump wells in Thiawor. With expected population increase, household demand will undoubtedly pose new dilemmas in water security in the future. While hand dug wells are an inexpensive and independent option for sourcing water in a small local scale, an increasing population may create a strain on resources.

A benefit of the study test design is that all of the participants used knowledge of their own practiced water retrieval methods to assist in conducting the study. No additional training was required except for an explanation of timing and organization by the author. All materials used in the pumping test were locally sourced, save for the measuring tape which was sent. However, a similar tape may easily be found locally in future planning. Both of these factors could have implications for future design models involving local-level participation or reproduction conducting similar studies. A similar series of tests could easily be reproduced by trained Senegalese to gather data for later analysis by regional government, NGOs or trained professionals looking at the viability of certain water management systems in a village setting. Utilizing community members and local materials has potential to keep costs down in projects and actively involve community members in understanding their water system. This study method may be useful to revisit in the future for reproduction to determine local-level aquifer conditions and documenting water use. This method could be a way to get preliminary aquifer data by trained locals in rural areas and may be useful for future studies in rural settings.

\section{Interviews Discussion}

According to the IPCC 2014 report, "major future rural impacts are expected in the near term and beyond...these impacts are expected to disproportionately affect the welfare of the poor in rural areas." (IPCC \& Field, 2014) The first step to adapting to changes is to understand the current system of operation and management for these rural communities. This case study is just one of many introductory investigations that could be used to better inform policy-makers and scientists about how current water systems are being used by a rural community in Senegal. Thiawor is located in Tambacounda, consists of an underrepresented minority group, within one of the poorer regions of Senegal known for banditry, high incidences of malaria, and illegal forest fires that contribute to desertification of the Sahel (Courtwright, 2018).

Contribution to welfare of rural residents of Senegal include small gardens, which provide local nutritional supplements to diet that benefit health and well-being. Reduced access to nutritional foods and increasing food security may be connected to water access and availability. A noted decrease in compound garden establishment may have implications for rural community access to nutritional foods and food security. As one resident states: 


\section{"If they've pulled water in the morning, sometimes in the evening they don't take a turn. We do it sometimes like we'll pull in the morning and evening, but our drinking pots are drunk a lot. \\ Greetings are frequent here. We wash clothes. And that's why we haven't started a garden."}

Compound gardens or smaller-scale nutritional gardens are easier to maintain than larger projects away from the domestic circle. There is admiration and envy among those who wish to establish or reestablish their compound gardens. Most gardens are begun on a small scale, with seedlings to transplant and are watered with gray water. The four compounds that have gardens are pulling extra water to maintain them, which is an added burden on top of agricultural field work and domestic chores like cooking and cleaning. Thiawor is able to meet the demand of drinking water, but establishing gardening, as stated, there is an uncertainty in water available as well as energy to be applied. The lowered water table over time was cited as hampering the ability to maintain dry-season garden with traditional pulling methods. Interviewees noted changes in the last 12 years regarding seasonal rainfall - either delayed starts to the season or more intense rainfall events, which make planting and timing of crops difficult as a farming community. Additionally, two separate participants mentioned well water levels in the area dropping 8-10 meters in the last 60 years, citing well construction and maintenance over time. While these interviews are not able to delve into deeper climate change analysis, it offers commentary on the community perception of increasing water insecurity over time. Additional important factors such as increased water demand from population growth or as a result of increased water made available from a system is also not discussed in this study.

Water retrieval etiquette is that water must be split when labor has been performed together. The aforementioned reduction in seasonal gardens from 7 to 4 at present - a $43 \%$ decrease - leaves a possibility that water demands are only getting more difficult to meet. Delays and over 30 minutes of wait time at a water source has been directly linked to lags in economic prosperity and development, especially for women who are often the main producers of water for a household (UNICEF \& World Health Organization, 2012).

These interviews conducted highlight the current domestic water demands on a small village level. This gives an average household and per-person daily water usage. The demands and method of water retrieval also show the stressors placed on the wells - a twice-a-day demand to produce enough water for the village of just under 400 residents all from five working wells requiring a total of over 7,000 liters of water per day.

Limitations of the interviews may include human error in the stated quantified water usage may vary daily. They may also have been amounts that were disregarded, not included, or forgotten that add to the daily amounts mentioned. Additionally, the interviews were only completed in one season - peak rainy season - and thus it is possible that depending on the season, residents' opinion of needs may vary, or be restated as different depending on the changing water situation of the season. This study is limited to the quantification of water based off resident statements and not an actual monitored observation of a single household use.

As only rainy season recovery data was collected, it is difficult to draw conclusions about water scarcity or availability in the dry season in Thiawor. The season containing data is considered the most productive time of the year with regards to water availability. However, it may be argued that the discussion of water scarcity even in the rainy and productive season suggest that it is a problem even within the rainy season. While interviews cannot directly suggest that climate change is a factor in local wells going dry, regional rainfall trends in West Africa suggest that a decrease in rainfall, or less predictable or regular rainfall events could result in insecurity of water available due to the nature of the wells and their recharge method (Grace et al., 2018). Increasing rainfall unpredictability has potential to lead to domestic water use issues relating to household management or small-scale projects, and increased vulnerability to drought. Since impacts of drought on groundwater levels lags behind the failure of rain and surface water runoff, (which in turn is associated with reduction in groundwater recharge) small rural communities like Thiawor may be adversely affected by drought in the future, and or may not have a way 
of planning or mitigating this issue (Foster et al., 2006). There is currently no rainwater storage, nor deeper drilled or pump wells in Thiawor. As rainfall and stream water are normally responsible for the recharge of an unconfined aquifer, climate change could have a greater impact on those vulnerable communities that rely on surface water for their water source instead of deep confined aquifers.

Additional interview data to complement quantitative testing may be useful in developing future projects or understanding management systems needs in a community. Understanding the nuances of localized water use and access and its complex fluctuations or projected needs is important to designing a lasting management system.

\section{Future Work \& Recommendations}

This study observed even during rainy seasons that Thiawor residents experience water scarcity challenges, challenges that are more pronounced and severe during dry seasons. Despite the relatively long and embedded nature of the interview results outlined in this report, an additional set of interviews during the dry season would improve our understanding of local perceptions of seasonal water needs. Conducting future interviews - especially if future interviews are conducted by Senegalese nationals would be improved with an interviewer with who is natively fluent in Bambara and understands cultural context of the community.

The closest precipitation observations are collected in the regional capital of Tambacounda and the town of Kothiary Naoude, both of which are at least 16 kilometers away from the research site. Local rainfall events may differ, and thus in future a more accurate measurement of rainfall events could help understand local water conditions in Thiawor. Lack of accurate rainfall data makes it difficult to understand the microclimate that may affect Thiawor versus Kothiary or Tambacounda. More accurate monitoring of localized rainfall data is recommended in order to understand potential local rainfall patterns and water resources.

It is difficult to make projections or suppositions of future conditions with the limited available data collected; if this study were to be extended, an expansion of interviews and more thorough monitoring of water supplies for a household may be useful. Timing constraints during the author's Peace Corps service contributed in part to the inability to obtain multi-season pump test data. It would be beneficial to collect an entire year data inclusive of all seasons. For accuracy in future studies, static water level should be measured days in advance multiple times; due to time constraints on well usage this would have been difficult but not impossible to coordinate within the village. Additionally, analysis of soil samples may be used to gain an understanding of local pedology. Lack of access to a lab or institute within the region of Tambacounda created barriers to data collection and sampling.

As there is evidence of direct correlations between drought proneness and poverty, water storage capabilities and preparedness for rural communities most affected is of utmost importance (Foster et al., 2006). Similar to the Shonsey (2009) study conducted in Mali (Shonsey \& Gierke, Quantifying available water supply in rural Mali based on data collected by and from women, 2013), a future MODFLOW/watershed simulation for the entire Senegal-Gambia river basin may be useful and provide a more in-depth look at water sources, or at least diversified water sourcing, management, or storage for the village of Thiawor. This could inform future water supply and provide insight on current management systems within the region. A hydrologic simulation model could also potentially predict what the daily water yield may be or guide best practices of installing a particular system in a village.

\section{Conclusions}

Like all countries, Senegal is interested in providing water access to all their citizens. But with a large percentage of their population still in rural poverty (and with projections of increased temperatures and decreased precipitation rates), there is increasing insecurity for these communities. Conducting small 
scale inquiries can help inform Senegalese responses in policy making, development project planning from NGOs, and local-level responses and adaptations to a changing environment. From this small interview sample, daily average water use needs per compound in a small rural village has been quantified by the residents. Domestic water purposes are also understood, as well as the method of water retrieval and times of day when the wells are most stressed. The most common domestic uses of water are: Drinking water, cooking, washing clothes \& household cleaning, watering animals and gardens. Domestic water needs are perceived as currently met in the rainy season according to interviews. Water scarcity and insecurity of availability has been discussed as a barrier to investment in small-scale gardening projects.

Domestic water use needs are generally met at the village level in the rainy season; some households partake in water-catchment systems using rainfall runoff from zinc roofs to assist with water retrieval. Water retrieval issues are considered less of an issue during the wet $\&$ rainy season within the wells. However, it is noted that there are still issues related to water scarcity even in the rainy season, and also with water quality. There is no other form of water source diversity or management system in place to enable Thiawor to store or retrieve water both domestically and agriculturally. As Thiawor relies on rain-irrigated agriculture, any fluctuation in the climate conditions will directly impact their water system, putting them at a higher vulnerability (Serdeczny, 2016). Average compound consumption in Thiawor is 540 liters per day, for an estimated total village consumption of 7,560 liters per day, or 5.25 liters per minute needed to meet daily demand. While average domestic demand in the village at present is met, should more water be made available it is possible demand and allocated purposes may also increase to meet greater accessibility. Ever-changing conditions like increased population and urban sprawl also create the possibility of greater demand in the future, regardless of whether an improved water pumping system is in place before demand increases.

Pumping tests were performed at the end of the rainy season, so it is assumed that this time of year is when the wells are at peak productivity. Through oral interviews it has been established that wells do frequently go dry, although it depends on the season (more frequently during the dry and hot season). The hydraulic conductivity estimated from the pumping tests suggest that the wells are all within a similar fine to coarse grain sandy aquifer material. Four of the wells data were able to calculate maximum yield to understand how hypothetically efficient they may be pumped under ideal conditions. The wells maximum pumping rate ranged from 49 to $72 \mathrm{lpm}$, well above the cited $5.25 \mathrm{lpm}$ needed at present. Based on usage and cultural appropriateness, the Diawara well would be most suitable to place a management system. Not only is it considered clean and potable, the well is located within the chief's compound which is heavily trafficked and constantly occupied.

With large climate variability within the Sahel, increasingly unpredictable rainfall patterns, and a shorter or more unpredictable agricultural season, small subsistence communities like Thiawor have greater vulnerability to these changes (Sarr et al., 2015). Understanding seasonal water availability for gardens could affect economic growth at the village level toward vegetable production and increase food security for residents.

Rainfall is the primary source of recharge in these hand-dug wells, so any variability or decrease can affect populations that do not have access to deep well aquifers or alternative sources of water. It is necessary to understand local aquifer characteristics before applying pumping systems without understanding their longevity or viability. This can result in wasted development money and projects, and inadequate solutions to resolve problems. Involving communities actively in their water system solutions will educate populations and enable and empower them to create their own management processes and better interact with their environment. Information about their aquifer such as transmissivity, flow rates, and the fluctuation of these seasonally may allow for efficient strategies to local conditions to be developed. Interdisciplinary studies involving participation of motivated local actors allows for greater depth of knowledge and understanding of local groundwater conditions on multiple scales. Improvement and more frequent studies of vulnerable communities may provide key information for future projects and mitigation measures. 


\section{Works Cited}

Adriansen, H. K., \& Nielsen, T. T. (2002). Going Where the Grass is Greener: On the Study of Pastoral Mobility in Ferlo, Senegal. Human Ecology, 215-226.

Batjes, N. (2019, October 17). SOTER-based soil parameter estimates (SOTWIS) for Senegal and The Gambia. Retrieved from ISRIC World Soil Information: https://data.isric.org/geonetwork/srv/eng/catalog.search\#/metadata/a6320590-0899-4b60bf4d-f80282bbb72c

Courtwright, J. (2018, June 5). Illegal logging and poverty fuel local tensions in southern Senegal . Retrieved from Equal Times: https://www.equaltimes.org/illegal-logging-andpoverty-fuel?lang=en\#.XXKnw5NKh-U

Dai, A., Lamb, P. J., Trenberth, K. E., Hulme, M., Jones, P. D., \& Xie, P. (2004). The recent Sahel drought is real. International Journal of Climatology, 24, 1323-1331.

Dietz, Ruben, \& Verhagen. (2004). The impact of climate change on drylands. With a Focus on West Africa. Dordrecht, The Netherlands: Kluwer Academic Publishers.

Domenico, P., \& Schwartz, F. (1990). Physical and Chemical Hydrogeology. New York: John Wiley \& Sons.

Dougherty, D. E., \& Babu, D. K. (1984). Flow to a partially penetrating well in a double-porosity reservoir. Water Resources Research, 1116-1122.

Earth Resources Observation and Science (EROS) Center. (2019, November 11). Retrieved from West Africa: Land Use and Land Cover Dynamics - Ecoregions and Topography of Senegal: https://eros.usgs.gov/westafrica/ecoregions-and-topography/ecoregions-andtopography-senegal

Faye, C. (2019). Precipitation trends in the Gambia River Basin. Glasnik Sprpskog drustva, 4557.

Field, Barros, Dokken, Mach, Mastrandrea, Bilir, ... White. (2014). Climate Change 2014: Impacts, Adaptations, and Vulnerability. Part A: Global and Sectoral Aspects. Contribution of Working Group II to the Fifth Assessment Report of the Intergovernmental Panel on Climate Change. Cambridge, United Kingdom and New York, NY, USA: Cambridge Univesity Press.

Foster, S., Tuinhof, A., \& Garduno, H. (2006). Groundwater Development in Sub-Saharan Africa. Sustainable Groundwater Management: Lessons from Practice. Washington DC: World Bank.

Funk, C., Rowland, J., Adoum, A., Eilerts, G., Verdin, J., \& White, L. (2012). Famine Early Warning Systems Network - Informing Climate Change Adaptation Series: A Climate Trend Analysis of Senegal. Rolla Publishing Service Center.

Gierke, Gross, Myre, \& Kome. (2008). A Technologically Appropriate Method for Measuring the Specific Capacity of Rope-Pump Wells. Houghton: Michigan Technological University.

Gomo, M., Kotze, Y., \& Danie, V. (2019). Large diameter hand-dgu wells in South Africa. Water Policy, 197-205.

Grace, K., Hertrich, V., Singare, D., \& Husak, G. (2018). Examining rural Sahelian outmigration in the context of climate change: a multimethodal analysis of the linkages between rainfall and outmigration in two rural villages from 1981-2009. World Development, 187-196.

Gross, E. (2008). A manual pumping test method for characterizing the productivity of drilled wells equipped with rope pumps. Houghton, MI: M.S. Thesis, Department of Geological 
and Mining Engineering Sciences, Michigan Technologica University. Retrieved from https://www.mtu.edu/peacecorps/programs/geo-mitigation/pdfs/essa-gross-thesisfinal.pdf

Hoerling, M., Hurrell, J., Eischeid, J., \& Phillips, A. (2006). Detection and attribution of twentieth-century northern and southern African rainfall change. Journal of Climatology, 3989-4008.

International Labour Organization. (2020, June 21). Unemployment, total (\% of total labor force) (modeled ILO estimate) - Senegal. Retrieved from The World Bank:

https://data.worldbank.org/indicator/SL.UEM.TOTL.ZS?end=2016\&locations=SN\&start $=2005 \&$ view $=$ chart

IPCC, \& Field, C. V. (2014). Climate Change 2014: Impacts, Adaptation and Vulnerability. Cambridge: Cambridge University Press. Retrieved September 18, 2019, from https://www.ipcc.ch/site/assets/uploads/2018/02/ar5_wgII_spm_en.pdf

Ludeke, M. K., Petschel-Held, G., \& Schnellnhuber, H.-J. (2004). Syndromes of Global Change: The First Panoramic View. GAIA - Ecological Perspectives for Science and Society, 4249.

Moench, A. F. (1997). Flow to a well of finite diameter in a homogeneous, anisotropic water table aquifer. Water Resources Research, 1397-1407.

Moench, A. F. (1998). Correction to 'Flow to a well of finite diameter in a homogeneous, anisotropic water-table aquifer'. Water Resources Research, 2431-2432.

Mohapatra, S., Ratha, D., \& Cisse, F. (2011). Remittance Markets in Africa. In Remittance Markets in Africa (pp. 221-239). Washington, DC: World Bank.

Myre, E. (2008). The significance of casing storage in tests of drilled wells equipped with rope pumps. Houghton, MI: M.S. Report, Department of Civil and Environmental Engineering, Michigan Technological University.

Ndione, Sambou, Sane, \& Kane. (2017a). Shift and Trend in Rainfall Time Series under Climate Variability and Change: Case of Senegal. Journal of Geoscience and Environment Protection, 31-53.

Ndione, Sambou, Sane, Kane, Leye, Tamba, \& Cisse. (2017b). Statistical analysis for assessing randomness, shift and trend in rainfall time series under climate variability and change: case of Senegal. Journal of Geoscience and Environmental Protection, 31-53.

Ndour, P., Kane, A., Niang, A., \& Lazar, G. (2012). Rainfall variability in Senegalese rural area: Implications on water resources in the borough of Fimela. Environmental Engineering and Management Journal, 2239-2247.

Randall, S., \& Coast, E. (2015). UN Census "Households" and Local Interpretations in Africa Since Independence. $S A G E, 1-18$.

Reulland, Ardoin-Bardin, Collet, \& Roucoud. (2012). Simulating future trends in hydrological regime of a large Sundano-Sahelian catchment under climate change. Journal of Hydrology.

Ribot, J. C. (1999). Decentralisation, participation and accountability in Sahelian Forestry: Legal Instruments of Political-Adminiatrative Control. Africa: Journal of the International African Institute, 23-65.

Sarr, M. A., Gachon, P., Seidou, O., Bryant, C. R., Ndione, J. A., \& Comby, J. (2015). Inconsistent linear trends in Senegalese rainfall indices from 1950 to 2007. Hydrological Sciences Journal, 1-32. 
Schlüter, T. (2006). Geological Atlas of Africa With Notes on Stratigraphy, Tectonics, Economic Geology, Geohazards and Geosites of Each Country. Springer, Berlin, Heidelberg.

Serdeczny, O. (2016, January). Climate change impacts in Sub-Saharan Africa: from physical changes to their social repercussions. Regional Environmental Change.

Shonsey, C. (2009). Quantifying available water at the village level: A case study of Horongo, Mali, West Africa. Houghton MI: M.S. Report, Department of Civil and Environmental Engineering, Michigan Technological University.

Shonsey, C., \& Gierke, S. J. (2013). Quantifying available water supply in rural Mali based on data collected by and from women. Journal of Cleaner Production, 43-52.

Sissokho, K., van Keulen, H., Verhagen, J., Tekken, V., \& Battaglini, A. (2011). Agriculture, livelihoods and climate change in the West African Sahel. Regional Environmental Change, 119-125.

Sterrett, R. J. (2007). Groundwater and Wells. New Brighton MN: Johnson Screens.

Tappan, G., Sall, M., Wood, E., \& Cushing, M. (2004). Ecoregions and land cover trends in Senegal. Journal of Arid Environments, 427-462.

The World Bank. (2019, April 13). Retrieved from Senegal Overview: https:/www.worldbank.org/en/country/senegal/overview

The World Factbook. (2020, August 6). Retrieved from Central Intelligence Agency: https://www.cia.gov/library/publications/the-world-factbook/geos/sg.html

Toure, N. M., Kane, A., Nedeff, V., \& Lazar, G. (2010). Utility of GIS Applications in the study of the use and water quality on the Petite Cote of Senegal. Journal of Engineering Studies and Research, 48-58.

UNICEF, \& World Health Organization. (2012). Progress on Drinking Water and Sanitation. Joint Monitoring Programme, 31.

United Nations, D. P. (2019). United Nations World Population Prospects 2019. Retrieved from United Nations: https://population.un.org/wpp/Graphs/Probabilistic/POP/TOT/686

Verhagen, J., Put, M., Zaal, F., \& van Keulen, H. (2004). Climate Change and Drought Risks for Agriculture. In A. J. Dietz, R. Ruben, \& A. Verhagen, The Impact of Climate Change on Drylands. Dordrecht: Springer.

WHO/UNICEF. (2019). Data: Senegal. Retrieved from WHO/UNICEF Joint Monitoring Programme for Water Supply and Sanitation: washdata.org

World Bank. (2019, November 7). Remittance Inflows to GDP for Senegal. Retrieved from FRED, Economic Research Federal Reserve Bank of St. Louis: https://fred.stlouisfed.org/series/DDOI11SNA156NWDB 